2. LOS PROBLEMAS DE LA DISTRIBUCIÓN TERRITORIAL DEL PODER EN ESPAÑA. LA REFORMA DEL SENADO

FAUSTINO FERNÁNDEZ-MIRANDA ALONSO

Profesor Titular de Ciencia Política

UNED 


\section{SUMARIO}

I. Antecedentes. - II. Naturaleza del Estado en la ConstituCION DE 1978. INTRODUCCION.-A. El Estado Autonómico como Estado compuesto. B. Esquema de un Estado compuesto. C. Aplicación del esquema al Estado español. III. El Estado AutoNÓMICO COMO PROCESO DOBLE Y ABIERTO. EL PRINCIPIO DE voluntariedad.-IV. Pproblemas derivados de UN hipotético fiN DEL PROCESO. LA SIMULTANEIDAD DE LA INTEGRACIÓN EN EUROPA. V. EL ESTADO DE LA CUESTION EN EL MOMENTO ACTUAL.-A. Reforma de los Estatutos. B. Reforma de la Constitución. C. Reforma del Reglamento del Senado. VI. ANALISIS DE LAS PROPUESTAS DE REforma del Reglamento del Senado.-A. Cuestiones previas. B. Delimitación del tema. C. Cuestiones procedimentales. D. Propuestas de los Grupos Parlamentarios. 1. Propuesta del Grupo Parlamentario Socialista para la reforma del Reglamento del Senado (18 de abril de 1990). 2. Proyecto de territorialización del Senado del Grupo Popular (22 de marzo de 1990). 3. Propuesta de reforma del Reglamento del Senado del Grupo Parlamentario Centro Democrático y Social (26 de marzo de 1990). 4. Borrador de propuesta de reforma del Reglamento del Senado en relación con la Comisión de Comunidades Autónomas del Grupo Parlamentario Mixto (Iniciativa per Catalunya-Izquierda Unida) (22 de marzo de 1990). 5. Propuesta para la reforma del Reglamento del Senado, orientada a la consolidación de su carácter de Cámara territorial, del Grupo Parlamentario Convergència i Unió (26 de marzo de 1990). 6. Documento elaborado por el Grupo Parlamentario de Senadores Nacionalistas Vascos en relación con la posible reforma del vigente Reglamento de la Cámara (26 de marzo de 1990). E. Análisis global de las propuestas. F. Acuerdo de la Ponencia. Cuadro sobre los contenidos de las Propuestas de los Grupos Parlamentarios del Senado respecto a la reforma de la Cámara. VII. Consideraciones FINALES. 
Revista de Derecho Político, núm. 34, 1991, pp. 71-121

\title{
2. LOS PROBLEMAS DE LA DISTRIBUCIÓN TERRITORIAL DEL PODER EN ESPAÑA. LA REFORMA DEL SENADO
}

\author{
POR \\ FAUSTINO FERNÁNDEZ-MIRANDA ALONSO \\ Profesor Titular de Ciencia Política
}

UNED

I. ANTECEDENTES ${ }^{\top}$

Uno de los problemas más graves del establecimiento del Estado liberal en España, vino determinado por la dificultad que, de modo continuo, suscitó la distribución territorial del poder; la debilidad del nuevo Estado

1 Los estudios doctrinales sobre el problema de la distribución territorial del poder en nuestra historia contemporánea, son muchos, valiosos y enfocados desde distintas perspectivas. No es mi intención repetir, por tanto, estos análisis sino resaltar determinados aspectos importantes para el desarrollo del estudio. Es decir, se pretende efectuar un recorrido histórico significativo para poner de relieve no sólo la situación previa a la desaparición del unitarismo, sino también las fórmulas —que no fórmula - previstas en la Constitución; se trata de señalar cómo siguen latiendo, consciente o inconscientemente, táctica o estratégicamente, ideas que, reciprocamente dadas por inadmisibles y excluyentes, han logrado convivir en nuestra situación actual.

Para una visión global, vid., entre otros: J. TusseLL GómEz: La reforma de la Administración Local en España (1900-1936), Madrid 1973; J. OlavarRI GoRTÁzAR: “La cuestión regional en España (1808-1939)", en La España de las Autonomias, Espasa-Calpe, Madrid 1981; L. VANDELLI: El ordenamiento español de las Comunidades Autónomas, IEAL, Madrid 1982; A. GuAITA MARTORELL: «Reflexiones sobre el tratamiento constitucional de la provincia desde 1812 hasta la vigente Constitución de 1978 (mención especial de Extremadura y Cataluña)", en Estudios sobre la Constitución española. Homenaje al profesor E. García de Enterria, tomo IV, Civitas, Madrid 1991; A. BALCELLS: El nacionalismo catalán, Historia 16, Madrid 1991. 
desde su origen, impidió una realización eficaz de las ideas de centralización y unitarismo típicas de esta forma política, que permitiera servir de cauce a los procesos de centralización e igualación. La pervivencia de los planteamientos del Antiguo Régimen sobre la distribución territorial del poder hacen que ésta se realice de modo lento, nunca finalizado y permanentemente conflictivo.

Por otro lado, el sentimiento localista, exacerbado por el traslado de la familia de Carlos IV a Francia y la subsiguiente reacción de las Juntas Generales, que a sí mismas se denominaron soberanas, generó, junto al patriotismo, un sentimiento de autogobierno que, por los avatares de la guerra, duró en el tiempo y enraizó en las mentalidades de una sociedad no excesivamente culta. La aparición y desarrollo en España, hacia la mitad del siglo XIX, de planteamientos ideológicos de nuevo cuño, desarrollados fundamentalmente en el seno del partido demócrata, añade una nueva dimensión al problema. Por descontado, y más referido a lo expuesto en primer lugar que en el segundo, las guerras carlistas suponen una reacción frente al intento centralista y unitario del Estado liberal.

Esta problemática se mantiene de modo continuo a lo largo de toda nuestra reciente historia, y es preciso resaltar, en esta primera etapa de implantación del nuevo Estado, no sólo los aspectos regionales sino también el desarrollo del espíritu localista dentro de, y frente a, los territorios de mayor amplitud que, por causas históricas o ideológicas, surgirán. Es decir, para tener una visión cabal del conjunto, conviene señalar no sólo el aspecto de los agravios históricos generados por la centralización, sino también las ideologías críticas frente a ese centralismo propio del Estado liberal; es claro que ambos aspectos - de origen distinto-, tienen un punto de referencia común: muestra de ello es la votación favorable de los diputados carlistas al Proyecto de Constitución Federal de $1873^{2}$. De ahí la problemática de la organización territorial del poder en España, a lo largo de toda nuestra historia contemporánea; los intentos van desde los Proyectos de José Bonaparte ${ }^{3}$, a las previsiones centralistas de la Constitución de 1812 (artículo 10) nunca aplicadas, salvo en el trienio liberal, hasta el Decreto de 27 de enero de 1822 y la provincialización de Javier de Burgos en 1833. Estas divisiones iban acompañadas de la incorporación de una Administración Central, asentada en la periferia, que disminuía sustancialmente las atribuciones propias de las entidades locales, fueran ayuntamientos, partidos o diputaciones. Por ello, el unitarismo de moderados y progresistas encontró durante el reinado de Isabel II, la oposición doctrinal de carlistas e intelectuales demócratas de signo federal: los primeros, «partidarios de mantener y desarrollar las tradiciones políticas propias de la

1967:

2 Vid. C.A.M. Hennessy: La República federal en España, Aguilar, Madrid

3 A. Melon de Gordezuela: «El mapa prefectural de España», Revista de Estudios Geográficos, núm. 13, 1952, pp. 5-72. 
España del Antiguo Régimen, habian salido de la guerra de 1833-40 como defensores de los fueros»; los segundos, porque su idea «representaba lo que puede ser uno de los últimos progresos del pensamiento europeo" 4 . A estas ideas anticentralistas de signo tan distinto, se añadieron, según algún autor, otras doctrinas del mismo carácter como el organicismo krausista y el tardío influjo de la Vieja Escuela del Derecho Histórico ${ }^{5}$.

El fracaso de la República Federal supuso el olvido temporal de estas doctrinas, al menos en la España oficial, pasándose a actitudes unitaristas durante toda la Restauración. Sin embargo, ahí seguía el problema y así, aun con modificaciones y recortes, sobrevivieron los regimenes forales en Navarra y Vascongadas. Debido a esa pervivencia del conflicto y pese a las resoluciones restrictivas frente a los problemas forales, en la Restauración van a producirse hechos importantes desde el punto de vista politico:

1. La aparición y desarrollo de los nacionalismos catalán y vasco, siendo aquél el que logra tener una influencia real en los planteamientos, más o menos descentralizadores, de la última etapa de la Restauración. Sirva como ejemplo el programa reformista de Francisco Silvela en 1890, base de los posteriores proyectos del partido conservador.

2. Dentro de los proyectos de este partido, destaca el de Antonio Maura, muy discutido entre 1907 y 1909; en él se fortalecen las atribuciones y acuerdos de las Diputaciones y se reivindica el genuino sentido de la región como algo distinto de la provincia, con sus propios órganos de gestión: por primera vez no se habla de provincias.

Este proyecto Maura, que no llegó a ser aprobado, sirvió de base al tema de las mancomunidades en 1913; por Decreto de 26 de marzo de 1914, se aprobó la Mancomunidad catalana, cuya presidencia ocupó Prat de la Riba.

3. En los años 1918 y 1919 se realizaron otros intentos, bajo los Gobiernos de Dato, Garcia Prieto y Romanones; todos ellos fracasaron, por razones que no vienen al caso.

Sirva lo expuesto hasta aquí para señalar cómo no sólo no se había resuelto, a lo largo de los siglos XIX y principios del XX, el problema de la distribución territorial del poder, sino que se manifiesta, además, en una

4 R. CARR: España 1808-1939, Ariel, Barcelona 1970, 2. ${ }^{a}$ ed., pp. 303.

5 J. F. Lorca Navarrete: Pluralismo, regionalismo, municipalismo. Sevilla 1978 , pp. 81 y ss. 
nueva faceta: con fuerzas políticas -claramente dominantes en el caso catalán-que representaban sectorialmente el conflicto, y ponian en tela de juicio la propia existencia del Estado. Creo que es desde esta perspectiva como ha de observarse la actitud de las Constituyentes republicanas de 1931, que tuvieron que hacer frente al problema en circunstancias de sobra conocidas ${ }^{6}$.

Como acertadamente señala Santiago VARELA, la experiencia de la II República supone la primera vez en nuestra historia en que "a partir de un régimen democrático y parlamentario se hizo un esfuerzo por superar la contradicción ... del liberalismo español del siglo XIX que no supo ser liberal con las regiones" ?

El problema más grave con el que se encontraron las Constituyentes de la II República, vino determinado por la ausencia de un sistema de partidos común a todo el territorio nacional; la existencia de partidos regionales, mayoritarios en algunas regiones - véase sustancialmente el caso de Cataluña y en menor medida del País Vasco- implicaba el temor de que la redistribución territorial del poder dentro del Estado, tuviera como consecuencia el que, determinadas áreas territoriales, iban a quedar bajo el mando de fuerzas políticas ajenas ${ }^{8}$.

El olvido de la fórmula federal al igual que la del fracasado unitarismo, condujo al original Estado integral. Es curioso constatar que partidos de vocación claramente federal, ligados a la tradición republicana y socialista, llegado el momento, renunciaran a planteamientos federales; igualmente, partidos conservadores - CEDA - con profesión de fe regionalista, se manifestaran sumamente reticentes al respecto, cuando no hostiles. Este hecho singular es importante para entender la ambigua y compleja fórmula aplicada en la Constitución de 1931; es asimismo una clave nada despreciable para comprender lo que sucedería - cuarenta y siete años después- en la elaboración del texto de 1978.

El centralismo exacerbado del régimen político nacido de la guerra civil, no sólo impidió el desarrollo de la problemática de la distribución territorial del poder sino que posibilitó, hasta cierto punto, una unión entre las fuerzas políticas fuera del régimen, justificada pero curiosa: la asunción por todos los partidos antifranquistas de carácter nacional, de las reivindicaciones autonomistas de los partidos de signo nacionalista territorial ${ }^{9}$.

- Vid. S. VARELA: El problema regional en la // República española, Unión Editorial, Madrid 1976; J. Oliver ARAuJo: El sistema político de la Constitución española de 1931, Universitat de les Illes Balears, Palma 1991.

'Op. cit., p. 14.

a Vid. S. VARELA: op. cit., pp. 29 y ss.

๑ En la última etapa del régimen franquista, la opinión pública manifestaba también la importancia que poseía el tema regional. Vid. S. DEL CAMPo, M. NAVARRo y J. F. TEZANOS: «Los españoles ante la cuestión regional», Sistema, núm. 13, 1976. 
En cambio, como ha puesto de relieve DE BLAS GUERRERO, la concepción de la política regional por parte de los dos partidos más significativos de la izquierda - PSOE y PCE- era radicalmente indefinida, si no confusa, en el momento de abordar la elaboración de la Constitución ${ }^{10}$. Por ello, en este momento y en lo que a la cuestión regional afecta, se incorporaron criterios de muy diverso género y especie por parte de las fuerzas políticas que provenian de la oposición al franquismo; a su vez, el centro derecha o la derecha también poseian sus propias ideas al respecto, que incluso habian inspirado, aunque en un ámbito exclusivamente administrativo, el desarrollo de políticas regionales en la etapa anterior. Quizá esas ideas regionalistas, puestas al día, encuentran una perfecta expresión en "Tácito» donde se afirma lo siguiente, refiriéndose al tema regional:

«Pero parece necesario afrontar su análisis y señalar que, con pleno respeto a los postulados políticos más ortodoxos, pueda pensarse en un planteamiento regional $-y$ no simplemente administrativo- sin que afecte en absoluto a la unidad nacional, que constituye principio básico e irrenunciable, y que es preciso dar los pasos necesarios en esa dirección. Pero digámoslo una vez más, que éstos se lleven a cabo con verdadero espíritu regionalista y no con pretensiones simplemente "administrativas", que a veces nos hacen creer que el propósito que animan estas intervenciones, como ocurre en otras esferas, es aparentar que todo cambia para que todo siga igual»" ".

No es de extrañar, por tanto, que el gran debate sobre la forma de Estado, desde la perspectiva territorial, se desarrolle en torno a la palabra «nacionalidades», pues creo que era valor entendido - cada uno desde sus planteamientos - que en esa palabra se iba a sustanciar la naturaleza de las entidades territoriales - unas pocas o, en su caso, todas-que se constituyeran en el nuevo Estado ${ }^{12}$; el debate sobre esa palabra en las Constituyentes de 1978 puede reconducirse al que tuvo lugar en las de 1931 respecto al Estado integral. Cuestión más compleja fue la discusión sobre el reparto concreto de competencias que se iba a efectuar en el Título VIII, dadas las diferentes pretensiones, prevenciones, suspicacias, etc., de cada una de las fuerzas políticas alli representadas y superado el escollo del articulo 2. Como no podia ser menos, el resultado obedeció a la superpo-

10 «El problema nacional-regional español en los programas del PSOE y PCE», REP, núm. 4, 1978.

${ }_{11}$ Ibérico Europeo de Ediciones, S. A., Madrid 1975, p. 68.

12 Vid. D. S. Congreso de los Diputados. Comisión de Asuntos Constitucionales y Libertades Públicas, núms. 59, 60-61-66 (5, 8, 9 y 12 de mayo de 1978, respectivamente), en Constitución española, Trabajos parlamentarios, tomo I, Cortes Generales, Madrid 1980. 
sición de planteamientos diversos y, casi se podría afirmar, antagónicos: el consenso permitió diversas yuxtaposiciones y obligó a dejar el problema abierto a un proceso a realizar una vez que entrara en vigor el texto constitucional.

En resumen, durante el proceso constituyente no existió un modelo global respecto a la distribución territorial del poder dentro del Estado o, dicho de otra manera, un modelo autonómico unívoco, ni tampoco las fuerzas políticas, como ya se apuntó, mantuvieron posiciones permanentes a lo largo de todos los debates, y asi, por ejemplo, como resume TORRES DEL MORAL.

«1. Alianza Popular varió su posición desde la propuesta de una descentralización administrativa hasta la aceptación de la autonomía para las regiones, mientras mantenía aquella descentralización para las que llamaba Mancomunidades Provinciales.

2. Unión de Centro Democrático también varió su punto de vista. En un principio postulaba sólo la autonomía de las regiones históricas; después generalizó los procesos preautonómicos y propugnó la autonomia de provincias y municipios.

3. El Partido Socialista Obrero Español defendia desde hacia tiempo el modelo federal, pero se plegó posteriormente a una idea autonómica menos polémica.

4. El Partido Comunista también sostenia un modelo federal, conforme al cual las Cortes no debian de aprobar los Estatutos de Autonomia en su detalle de contenido sino sólo pronunciarse sobre su constitucionalidad.

5. Los partidos nacionalistas catalanes, aún más federalistas (incluso algún diputado o senador defendió la confederación), hablaban de un pacto entre naciones, unas competencias exclusivas del Estado central y competencia residual de las Comunidades Autónomas.

6. Similar posición sostenían el Partido Nacionalista Vasco y Euskadiko Ezquerra." ${ }^{13}$

Es significativo respecto a esta falta de criterio por parte de los constituyentes, la evolución sufrida, a lo largo de los debates, de la propuesta

${ }^{13}$ Principios de Derecho Constitucional español, Átomo, t. 2. ${ }^{\circ}$, Madrid 1989 , p. 309 . 
inicial del borrador de la Ponencia de la Comisión de Asuntos Constitucionales y Libertades Públicas del Congreso de los Diputados, en la que se definía y regulaba el Senado como auténtica Cámara territorial, representativa de las Comunidades Autónomas; esta propuesta será desustancializada de modo sistemático, en todo el iter legislativo del artículo 69, hasta llegar a la situación definitiva en la que, de modo claro, se regula el Senado como una Cámara de segunda lectura y de representación ideológica ${ }^{14}$.

\section{NATURALEZA DEL ESTADO EN LA CONSTITUCIÓN DE 1978}

\section{Introducción}

El resultado de los debates constitucionales en toda su variedad y extensión, pusó de relieve la falta global de acuerdo respecto a la configuración de la distribución territorial del poder en el nuevo Estado. Las discrepancias manifestadas en el debate del artículo 2 aventuraban ya la dificultad de una articulación coherente de esta cuestión. Por ello, no es de extrañar que, al final, nuestro Título VIII quedase redactado como la yuxtaposición de varios proyectos de organización territorial de diferente signo que, en consecuencia, no iban a poder ubicarse dentro de los distintos modelos doctrinales clásicos sobre distribución territorial del poder.

Asi, en principio, no es el modelo de Estado Regional diseñado en la Constitución italiana de 1947; aunque en parte se inspiró en la II República española, tampoco es equiparable a su confuso Estado integral; menos aún se acomoda a las teorias clásicas del Estado Federal. En resumen, pese a que un análisis detallado de las técnicas incorporadas a la redacción del Título VIII permiten observar influencias de los modelos anteriormente citados, el resultado último no responde a ninguno de ellos en su conjunto.

14 Vid. F. Fernández Segado: «La construcción del Senado en el proceso contituyente», REP, núm. 38,1984, p. 64. En un interesante análisis, el autor pone de manifiesto el sorprendente paso del Senado pertilado por el borrador de la Ponencia como esencialmente autonómico, a una Cámara de representación de las diferentes entidades territoriales -en el informe de la Ponencia- y que, por una enmienda in voce del diputado Alzaga, saldrá de la Comisión de Asuntos Constitucionales como una Cámara de representación provincial, llegándose "a un punto muy próximo al de partida, esto es, a un Senado que se encuentra prácticamente equiparado al que configurara la Ley para la Reforma Política de 4 de enero de 1977 , con la sola diferencia de haber sido sustituidos los senadores de nombramiento regio por este otro grupo - muy semejante cuantitativamente- de senadores de representación de las Comunidades Autónomas"' (p. 90). 
Por ello no es de extrañar la ausencia de una denominación sobre la organización territorial del poder implantada, aunque tampoco esto es exigible a una norma sino que es habitual tarea de la doctrina.

Entre los estudiosos, la controversia se ha movido siempre en torno a un tercer tipo de Estado que se ubicaría entre el Federal y el unitario y que, en cierta medida, recuerda al Estado característico del sistema implantado en la Constitución italiana de 1947, definido por AMBROSINI como Regional ${ }^{15} y$ difundido en la España preconstitucional por el profesor FERRANDO BADÍA, ${ }^{16}$, entre otros ${ }^{17}$. Sin embargo, esta denominación no tuvo éxito entre los constituyentes, debido a la negativa de los partidos nacionalistas de las Comunidades históricas a aceptar el término región para definir su territorio. Algunos diputados propusieron adoptar la denominación sintética de federal-regional; otros la de Estado unitario regionalizable, basándose en el hecho cierto de que la Constitución establecía un Estado unitario susceptible de ser configurado en regiones autónomas.

La negativa a aceptar la denominación de unitario parecia lógica por la carga política que implicaba, dado el Estado de tal naturaleza e hipercentralizado precedente; ya hemos apuntado cómo no se aceptó el término Estado regional por las Comunidades históricas, que preferian llamar "nacionalidades" a sus entidades. El término federal, aunque propuesto en los debates constituyentes, como hemos visto, fue radicalmente excluido del texto, por razones más emocionales que otra cosa en un sector de las fuerzas políticas, debido a la experiencia politica de la I República que llevaba tal nombre; así, hoy en día incluso, aunque cada vez menos, el término federal sigue siendo equivalente, para determinados sectores de

15 «Un tipo intermedio di stato tra l'unitario e il federale caratterizzato dallautonomía regionale», Rivita di Diritto Pubblico, Roma 1933.

${ }_{16}$ «Formas de Estado desde las perspectivas del Estado regional», IEP, Madrid 1956

17 Entre otros, vid:: O. Alzaga: La Constitución española de 1978 (Comentario sistemático), Ed. del Foro, Madrid 1978; T. R. FernÁnDEZ: «La organización territorial del Estado y la Administración Pública en la Constitución", en T. R. FERNÁNDEZ (coord.): Lecturas sobre la Constitución española, UNED, Madrid 1979, p. 352; L. SANChez Agesta: Sistema Político de la Constitución española de 1978, Editora Nacional, Madrid 1984. J. LEguINA VILLA: “Las Comunidades Autónomas», en A. Predieri y E. Garcia de Enterría: La Constitución española de 1978. Estudio sistemático, Civitas, Madrid 1980; L. ORTEga Álvarez: «El pluralismo político como criterio de reparto del ejercicio del poder público», RFDUC, núm. 4 (monográfico), 1981; G. Peces Barba: La Constitución española de 1978. Un estudio de derecho y política. Fernando Torres, Valencia 1981; R. MARTín Mateo: «Manual de Derecho Autonómico", IEAL, Madrid 1984; J. FERRANDo Badía,: El Estado Unitario, el Federal y el Estado Autonómico, Tecnos, Madrid 1986. 
la opinión pública, a cantonalimo y desmembración del Estado. En consecuencia, lo que nadie quería era definir el nuevo Estado según los modelos clásicos de federal, unitario o regional. En el momento actual se ha generalizado la denominación de Estado autonómico ${ }^{18}$, término impreciso y neutro que, si bien se basa en uno de los elementos que configuran la distribución del poder en el Estado español, nada precisa respecto a los modos, formas, intensidad e igualdad-desigualdad que pudiese implicar la nueva regulación.

En el fondo, lo que se pretende en este estudio es averiguar si realmente son válidos los esquemas tradicionales propuestos por la doctrina para incorporar las nuevas formas de organización del poder dentro del Estado, producidas a partir de la segunda guerra mundial, bien ex-novo, bien como consecuencia de la evolución sufrida por las estructuras de poder dentro de los Estados consolidados. Según el profesor MUÑOZ MACHADO «... en 1978 las diferencias jurídicas entre las formulaciones organizativas del regionalismo y del federalismo se habian aliviado de tal forma en todos los sistemas comparados que había perdido mucha de su significación la definición del Estado como federal, ya que lo sustancial, el contenido del poder autonómico y. sus garantías, ha venido a independizarse de manera ostensible de las calificaciones formales, de manera que el uso de uno de los conceptos en liza (Estado Federal o Regional) no remite siempre a un régimen jurídico perfectamente diferenciado, sino a sistemas de características bastante similares, por lo que la elección del modelo no es hoy una cuestión que revista la importancia de otros tiempos ${ }^{19}$.

Ya la doctrina clásica iniciada por Ph. ZORN y seguida por TREITSCHKE y H. HELLER ${ }^{20}$, había planteado la imposibilidad de distinguir diferentes formas de Estado en función de la distribución territorial del poder que en aquél se efectuase, por entender, por razones estrictamente jurídicas o políticas, que el Estado siempre sería uno, ya que la soberanía es elemento esencial de éste y significa poder supremo ilimitado; aunque pueda ser limitada en su ejercicio, internacional o constitucionalmente, tal limitación no puede alterar su unidad.

En la misma línea, aunque más matizada, se encuentra la Escuela de Viena; de lo que se trata, opinan, es de la existencia de diversos grados de descentralización dentro de un Estado, sea cual sea la denominación que reciba. Este planteamiento, recogido entre nosotros por GONZÁLEZ

18 J. Ferrando Badia: op. cit., pp. 233 y ss.

19 Derecho Público de las Comunidades Autónomas, vol. I, Civitas, Madrid 1982, p. 254.

${ }_{20}$ Vid. M. Garcia-Pelayo: Derecho Constitucional Comparado, Revista de Occidente, Madrid 1959, 5. ${ }^{a}$ ed., pp. 220 y ss. 
CASANOVA ${ }^{21}$, GARCÍA ARIÑO ${ }^{22}$ y GONZÁLEZ ENCINAR ${ }^{23}$, entre otros, no es desdeñable, sobre todo si atendemos a razones históricas en las que se puede observar un doble proceso en la evolución del Estado contemporáneo: de centralización en los Estados surgidos como federales y de descentralización, en mayor o menor grado, en los viejos Estados unitarios ${ }^{24}$.

\section{A. El Estado Autonómico como Estado compuesto}

En consecuencia, y sin rechazar la denominación neutra y generalizada de Estado autonómico, lo cierto es que nos encontramos ante un Estado compuesto ${ }^{25}$, con entidades poseedoras de competencias propias, que disponen de autonomía política para su gestión. Para analizar, por tanto, nuestro sistema autonómico, es preciso acudir a lo concreto; es decir, observar en qué medida y en qué forma se efectúa la distribución territorial del poder; hecho este examen en la formulación constitucional y en su operatividad práctica, deducir el grado de descentralización logrado, lo que permitirá, siempre en cierta medida, calificar el sistema de uno u otro modo. Si partimos de que se trata de un Estado compuesto, sea cual sea su naturaleza, ha de establecerse una relación entre dos entidades dentro del propio Estado: por un lado, el Estado Central o el Estado a secas p, como algunos han dicho, el Estado superior o Global ${ }^{26}, y$, por otro, las entidades territoriales que disponen de autonomia. Se trataría de la existencia de una doble tendencia a la unidad y a la diversidad.

Como ha escrito GARCIA PELAYO: "se trata de un Estado en el que la unidad y la diversidad, la centralización y la descentralización, se resumen en una unidad dialéctica caracterizada por una específica conexión de las relaciones de coordinación, supra y subordinación e inordinación,

\footnotetext{
21 Teoria del Estado y Derecho Constitucional, Vicens-Vives, Barcelona 1982.

22 «El Estado de las Autonomías: realidad política, interpretación jurídica», en La España de las Autonomías, tomo II, Espasa-Calpe, Madrid 1981.

${ }_{23}$ El Estado Unitario-Federal, Tecnos, Madrid 1985.

${ }^{24}$ Baste con hacer mención a la doctrina de los poderes implícitos, resultantes y sus consecuencias, en EE. UU y en la evolución suiza y alemana, en lo que se refiere a los Estados Federales; en cuanto al proceso inverso en los Estados Unitarios, vid. T. R. FERnández RodRiguez: «Las autonomias regionales. Tendencias europeas actuales», REDA, núm. 10, 1976.

${ }^{25}$ STC de 28 de enero de 1982 (BJC núm. 10), STC de 14 de junio de 1982 (BJC núm. 15) y STC de 20 de abril de 1983 (BJC núm. 25).

26 Vid. A. Torres del Moral: op. cit., p. 314.
} 
de tal manera que todas ellas se condicionan y complementan recíprocamente. Las solas relaciones de coordinación disolverían la unidad del Estado; las de supra y subordinación lo convertirian en un Estado centralizado puro y no sería posible la coexistencia entre ambos grupos de relaciones gracias a la idea de inordinación, la cual por sí sola es incapaz de fundar una entidad politica" ${ }^{27}$.

\section{B. Esquema de un Estado compuesto} rasgos:

Por tanto, un Estado compuesto ${ }^{28}$ se caracteriza por los siguientes

1. Existencia de una Constitución del Estado Central.

2. Existencia de relaciones juridicas entre las partes.

a) En las relaciones de coordinación el Estado Central y las entidades territoriales ocupan una posición de igualdad, desde las que se distribuyen coordinadamente las diferentes competencias propias del Estado unitario. De este modo, el ciudadano está sometido al poder del Estado central en las materias de su competencia, mientras que en otras se encontrará sometido al poder de la entidad territorial a la que pertenezca. Un segundo elemento de las relaciones de coordinación viene determinado por la duplicidad de Cámaras; . en una de ellas estarán representados los ciudadanos del Estado central en cuanto tales, mientras que en la segunda Cámara se encontrarían representadas las entidades territoriales como entidades autónomas. En principio ambas Cámaras se hallarian en relación paritaria.

b) Relaciones de supra y subordinación. En este segundo grupo de relaciones se manifestaría la supremacia del Estado Central sobre las entidades territoriales, pudiendo destacarse los siguientes extremos:

${ }^{27}$ M. Garcia-Pelayo: op. cit., p. 233.

2a Ibidem., pp. 231 y ss. Es obvio, por lo que a continuación se dice, que hemos hecho un traslado del esquema propuesto por García-Pelayo para el Estado Federal a lo que hemos venido denominando Estado compuesto. 
- Sometimiento de la norma suprema de las entidades autónomas a la Constitución general;

- primacía del Derecho del Estado Central;

- existencia de un Tribunal superior que resuelva los conflictos surgidos entre las partes;

- facultades coactivas del Estado para hacer cumplir el orden jurídico, en caso de incumplimiento por parte de las entidades territoriales;

- competencia del Estado central para supervisar y vigilar el funcionamiento de las entidades autónomas.

c) Relaciones de inordinación ${ }^{29}$. Dado que en un Estado compuesto se pretende realizar una sintesis entre un poder central y una pluralidad de poderes territoriales, este tercer tipo de relaciones harian referencia a la incorporación de las entidades territoriales autónomas, como tales, al conjunto total. Su manifestación sería la participación de las entidades territoriales, como personalidades autónomas, en la formación de la voluntad del Estado Central y en la reforma de la Constitución.

Partiendo de este esquema del profesor García Pelayo, cuya lógica interna considero irreprochable y de difícil, si no imposible, sustitución para un funcionamiento correcto de un Estado compuesto y señalando la admisión unánime, por parte de la doctrina española, con la denominación que se quiera, de la naturaleza compuesta de nuestro Estado autonómico, se impone analizar la Constitución para ver en qué medida se acomoda al esquema propuesto. Ello, en mi opinión, nos podria dar las claves para entender las disfuncionalidades que se aprecian en nuestro texto constitucional desde su promulgación, puestas de relieve por la práctica existente desde esa fecha.

\section{Aplicación del esquema al Estado español}

Voy a proceder, por tanto, a la aplicación del esquema señalado a nuestra regulación constitucional ${ }^{30}$.

${ }^{29}$ Se acepta esta expresión de «inordinación» aunque, desde el punto de vista filológico, no parece la más adecuada.

30 A pesar de los esfuerzos doctrinales, realizados hasta la fecha, por racionalizar nuestro Estado Autonómico de modo global, no se da una visión clara y simple de los elementos que lo forman; sin negar en absoluto la valiosidad de las aportaciones de la doctrina, creo que el esquema propuesto en este trabajo ayuda a entender nuestro Estado, en su complejidad. 
1. La Constitución de 1978 sería la Constitución del Estado Central, entendiendo éste en sentido global; la naturaleza de Estado compuesto vendría determinada por el artículo 2 del texto al señalar que «la Constitución se fundamenta en la indisoluble unidad de la Nación española, patria común e indivisible de todos los españoles, y reconoce y garantiza el derecho a la autonomía de las nacionalidades y regiones que la integran y la solidaridad entre todas ellas". El desarrollo de esta naturaleza compuesta del Estado se determina en el Título VIII y normas concordantes.

2. Las relaciones que vertebran este Estado compuesto serían las siguientes:

a) Relaciones de coordinación. Ya hemos visto que son aquellas en las que el Estado Central y los entes territoriales operan en plano de igualdad. En los artículos 148, 150 y 151 de la Constitución se recoge la distribución de competencias de un modo que, como mínimo, se ha de calificar de ambiguo y confuso; no se ha partido de manera clara de cualquiera de los procedimientos al uso en el Derecho Comparado y, en consecuencia, existen serias dudas respecto al alcance de determinadas cláusulas sumamente oscuras, aunque en el momento presente la doctrina ha realizado un gran esfuerzo para clarificar su alcance y los términos de tal distribución.

Los sistemas tradicionales aludidos consisten en distinguir entre materias exclusivas, bien del Estado central bien de los entes autónomos, y materias concurrentes en que participan ambas partes. A su vez, las primeras, pueden ser materias cuya legislación y ejecución pertenecen exclusivamente al Estado Central, materias cuya legislación y ejecución pertenecen a los entes territoriales, materias cuya legislación corresponde al Estado y su ejecución a los territorios autónomos y, por último, materias cuya legislación pertenece a las autonomías y su ejecución al poder central. En cuanto a las materias concurrentes, es decir, las que pueden ser ejercidas por una $u$ otra parte, pueden presentar varias alternativas: que los entes territoriales sólo puedan legislar cuando el Estado Central no lo haga; materias atribuidas en principio a los territorios pero sobre las que el Estado Central tiene competencias para ejercerlas a efecto de que posean una regulación unitaria; por último, materias cuya legislación básica pertenece al Estado Central y su desarrollo a las entidades territoriales.

Desde un punto de vista formal se pueden seguir, a su vez, dos sistemas: bien se enumeran las competencias del Estado Central dejando el resto para los entes autónomos, o bien, aunque menos habitual, se enumeran las materias exclusivas de los entes territoriales entendiendo que las demás corresponden al Estado Central. 
Este esquema, en teoría sencillo, se halla sumamente confuso en nuestra Constitución. Como expresión de tal complejidad ${ }^{31}$ transcribo la clasificación normativa realizada por el profesor TORRES DEL MORAL sobre la distribución de competencias entre Estado y Comunidades Autónomas en nuestra Constitución.

«1. El eje del sistema es el artículo 149.1 de la Constitución, que establece las materias que son, en principio, de competencias exclusiva de los órganos centrales del Estado.

2. Si ése es el eje, el motor está en los estatutos de Autonomía, que son los que ponen en marchar el autogobierno, asumiendo algunas o todas las competencias que le permite el artículo $148.1 \mathrm{y}$, en virtud de la primera cláusula residual (art. 149.3), también cualesquiera otras que no les estén prohibidas por su atribución exclusiva a los poderes centrales.

3. Realizada la anterior operación, la segunda cláusula residual, contenida en el mismo precepto, confiere al Estado Central la competencia sobre las materias no asumidas por los estatutos de Autonomía.

4. Como dice el Tribunal Constitucional, no toda referencia constitucional a los estatutos de Autonomía es un reconocimiento de competencia.

5. La inclusión de una materia en el artículo 81.1 de la Constitución como propia de Ley Orgánica determina la competencia legislativa central sobre ella, puesto que sólo la Cortes Generales pueden producir este tipo de ley. Pero puede haber desarrollo normativo y/o ejecutivo autonómicos.

6. Junto a la Constitución y a los estatutos de Autonomía, también las leyes pueden regular competencias no asumidas por los estatutos y no reservadas constitucionalmente al Estado Central. No obstante, los artículos 147 a 149 de la Constitución se erigen en límites para la postestad legislativa de las Cortes en este cometido.

7. Una vez establecido el reparto competencial, todavia las Cortes, como sabemos, pueden por ley marco atribuir facultades legislativas a las Comunidades Autónomas en materia de competencia central; y por ley orgánica, transferirles o delegarles competencias de titularidad estatal, como efectivamente se ha dicho. Viceversa, me-

${ }^{31}$ Complejidad derivada del intento de aunar criterios políticos muy dispares, asi como planteamientos ideológicos muy distintos y, por último, del carácter abierto del proceso, en el doble sentido que se señala. 
diante ley de armonización pueden excepcionalmente invadir competencias autonómicas.

8. Los decretos de traspaso de servicios no son títulos competenciales, no confieren la titularidad de una competencia. Esta titularidad debe tenerse por uno de los títulos antes referidos. Los mencionados decretos sólo marcan el comienzo del ejercicio de la competencia y tienen, eso sí, un valor interpretativo en caso de duda respecto de una función o acto.

9. Tampoco altera el cuadro competencial establecido la facultad estatal de gasto público y de subvención de organismos para su funcionamiento y para el desempeño de actividades determinadas. De lo contrario, todo terminaría pasando a la competencia de los órganos centrales dada su mayor capacidad de gasto.

10. De igual modo les está vedado a los poderes centrales modificar el sistema competencial apoyados simplemente en su procura del interés general o de la igualdad y libertad reales y efectivas, de las que habla el artículo 9,2 de la Constitución. Estos fines deben alcanzarse a través, y no en contra, del sistema de competencias fijado. Si la materia en cuestión ha sido asumida por un estatuto de autonomía como de competencia exclusiva de la Comunidad Autónoma, este título es normalmente prevalente a esas otras consideraciones, si bien el interés nacional puede determinar una actuación extraordinaria de los poderes centrales." ${ }^{32}$

En segundo lugar, dentro de la coordinación, hay que señalar la duplicidad de Cámaras. Nuestra Constitución establece unas Cortes bicamerales, calificando al Senado, en el artículo 69-1, como Cámara territorial. Ello parece apuntar, en principio, al significado que la Cámara posee en los Estados compuestos; en cambio su sistema de elección, así como su ámbito competencial hacen que sea una mera Cámara de, segunda lectura y de representación ideológica; por otro lado, se establece un bicameralismo desigual en favor del Congreso de los Diputados ${ }^{33}$.

32 Op. cit., p. 536. La complejidad de esta descripción se vería aumentada si se tiene en cuenta que no se trata de un plan ya cerrado sino de un proceso aún abierto.

${ }^{33}$ Aunque esta cuestión se examinará in extenso más adelante, aquí sólo se trata de poner de relieve que al definir el Senado como Cámara territorial, bien en la mente de los constituyentes o, si se prefiere, en la mens legis, tal definición abunda en el carácter compuesto que tiene el Estado, sin perjuicio del desarrollo, afortunado o no, que a tal territorialidad se le proporcionó. 
b) Relaciones de supra y subordinación. En primer lugar, tendriamos la exigencia de sometimiento de las normas superiores de los entes territoriales a la Constitución del Estado Central, cuestión que no ofrece dudas en nuestra regulación al tener aquéllas naturaleza de leyes orgánicas, aprobadas por las Cortes Generales (art. 146); sin embargo, es necesario matizar distintos tipos de procedimientos de elaboración, propuesta y aprobación. En segundo lugar, la primacía del Derecho del Estado Central viene determinada por el artículo 149-3 de la Constitución que dice expresamente que las normas del Estado... «prevalecerán, en caso de conflicto, sobre las de las Comunidades Autónomas en todo lo que no esté atribuido a la exclusiva competencia de éstas.... ${ }^{34}$.

En tercer lugar, la Constitución establece un Tribunal Constitucional, creado en el Título IX, al que expresamente se atribuye, en el artículo 161, el pronunciarse sobre los conflictos de competencia entre Estado y Comunidades Autónomas o de éstas entre sí. Por último, la inspección y vigilancia se encuentra recogido en el artículo 155 de la Constitución, al señalar que «si una Comunidad no cumpliere las obligaciones que la Constitución $u$ otras leyes le impongan o actuare de forma que atente gravemente al interés general de España, el Gobierno, previo requerimiento del presidente de la Comunidad Autónoma y, en el caso de no ser atendido, con la aprobación por mayoría absoluta del Senado, podrá adoptar las medidas necesarias para obligar a aquélla al cumplimiento forzoso de dichas obligaciones o para la protección del mencionado interés general. Para la ejecución de las medidas previstas en el apartado anterior, el Gobierno podrá dar instrucciones a todas las autoridades de las Comunidades Autónomas».

c) Relaciones de inordinación. Es en este tipo de relaciones donde son más patentes las disfuncionalidades de nuestro Estado compuesto, pues, como hemos visto, no se prevé la participación de las Comunidades Autónomas, como tales, en la formación de la voluntad del Estado, aunque en el artículo 69-5 se apunte, tímidamente y de forma marginal, un esbozo de participación de las Autonomias en el Senado, a través de los senadores elegidos por sus Asambleas legislativas. Lo mismo sucede con la participación autonómica en la reforma de la Constitución estatal mediante su

${ }^{34}$ Entre otros, vid. para esta cuestión: L. PAREJo ALFonso: «La prevalencia del Derecho estatal sobre el regional (el articulo 149,3 de la Constitución)", CEC, Madrid 1981; I. OTTO y PARDO, de: «La prevalencia del Derecho estatal sobre el Derecho regional», REDC, núm. 2, 1981; L. ToLIVAR ALAS: «El control del Estado sobre las Comunidades Autónomas», IEAL, Madrid 1981. 
iniciativa y, en la fase de aprobación, a través de las representaciones, ya señaladas, que ostentan en el Senado ${ }^{35}$.

De lo dicho hasta ahora se puede deducir que el esquema propuesto para un Estado de naturaleza compuesta, que reconoce entidades territoriales con personalidad propia, es aplicable a nuestra Constitución. Asimismo considero que la no adecuación en determinados aspectos, ya señalados, es generadora de disfuncionalidades, no sólo teóricas sino también prácticas, puestas de relieve en la realidad política cotidiana en los trece años de aplicación de la norma ${ }^{36}$.

Tales disfuncionalidades, criticables desde una perspectiva de lógica institucional, no lo son tanto si nos atenemos a las circunstancias históricas en las que fue elaborada la Constitución. Es posible, incluso, que no existiera otro camino, sobre todo si tenemos en cuenta que en el planteamiento originario se enfrentaban varias concepciones: centralistas residuales, aceptando como mal menor la realidad que se imponía; regionalistas, que englobaban hasta cierto punto la tradición derivada de la II República; federalistas de distinta índole (nadie precisó ni profundizó en qué tipo de federalismo se incardinaba), y también concepciones confederales en su sentido más estricto. Esta yuxtaposición de ideas, aliviadas por el consenso, dieron lugar a la compleja normativa existente.

\section{EL ESTADO AUTONÓMICO COMO PROCESO DOBLE Y ABIERTO. EL PRINCIPIO DE VOLUNTARIEDAD}

De lo señalado hasta ahora se desprende que el sistema establecido por la Constitución inició un proceso doble, no cerrado, que implicaba la territorialización del poder político y administrativo del Estado, determinando únicamente ciertas pautas de obligado cumplimiento en su desarroIlo. Pero, lo que ha de considerarse muy importante, al menos desde el punto de vista jurídico pues desde el punto de vista político tiene otra lectura, es que la unitariedad y centralización del Estado sería perfectamente mantenible si no se ejercían los derechos a la autonomía reconocidos en

${ }_{35}$ Vid. lo que se dice en la nota 61.

${ }^{36}$. Sirva como ejemplo la evolución de los índices de conflictividad, referidos exclusivamente a cuestiones planteadas ante el Tribunal Constitucional. Tales datos deben tomarse de modo indicativo, pues se refieren solamente a conflictos judicializados; la conflictividad política, en sentido estricto, merecería un análisis aparte. M.A.P.: Evolución de la conflictividad entre el Estado y las Comunidades Autónomas (1981-1989), Madrid 1991. 
el artículo 2 y desarrollados en el Título VIII. Por ello, al aprobarse el texto constitucional, se abrió un proceso de autonomización previsto por la propia norma: Título VIII, disposiciones transitorias ${ }^{37}$.

La Constitución, por tanto, no creó un Estado de estructura descentralizada sino que permitió esta organización, señalando las pautas a las que debería adecuarse. Este principio, llamado de voluntariedad o dispositivo ${ }^{38}$, implica el carácter renunciable del derecho a la autonomía $y$, en este sentido, se siguió un mecanismo similar al que; en su día, estableció la Constitución de 1931: en teoría podian coexistir territorios que ejercieran su derecho a la autonomía y otros que no, dependiendo e integrándose en el Estado Central.

En la elaboración práctica del mapa autonómico, al margen de razones constitucionales, han existido una serie de condicionamientos de hecho, preexistentes, y unos acuerdos entre las fuerzas políticas, efectuados extraparlamentariamente ${ }^{39}$; finalmente, y en función de la armonización pactada entre los grandes partidos, un mimetismo en los sistemas de autonomia de la mayoria de las regiones no históricas, en función de lo que. habría de ser este mapa. No es éste el momento de tratar sobre los distintos avatares y altibajos del proceso, sumamente estudiados por la doctrina ${ }^{40}$, pero lo cierto es que, en el momento actual, exceptuando los casos singulares de Ceuta y Melilla, nos encontramos con un mapa autonómico completo y cerrado; es decir, salvo la excepción señalada, hoy todos los ciudadanos del Estado español se encuentran bajo una doble dependencia: el Estado y su Comunidad Autónoma, sin entrar, por ser inadecuado metodológicamente, en otras dependencias de inferior rango territorial, como pudieran ser la provincia y el municipio.

Llegados aquí, podria afirmarse sin lugar a dudas, que el proceso autonómico ha finalizado ${ }^{41}$. Sin embargo, como he señalado, se trata de un doble proceso; la finalización del mapa autonómico no implica el carácter fijo y estático de tal proceso, pues éste posee otro aspecto de enorme importancia en el que nos encontramos: el no poco conflictivo ámbito com-

${ }^{37}$ Desde una perspectiva práctica, es necesario matizar que tal principio estaba ya, en el momento de la aprobación de la Constitución, sumamente condicionado por el establecimiento de las Pre-Autonomias.

${ }_{38}$ Vid. M. GaRcia CANALES: "La reforma de los estatutos y el principio dispositivo», REDC, núm. 23, 1988.

${ }^{39}$ Vid. Acuerdos Autonómicos. Servicio Central de Publicaciones de la Presidencia del Gobierno, Madrid 1981.

40 Vid. L. VANDELLI: «El Ordenamiento español de las Comunidades Autónomas", IEAL, Madrid 1982, y, en especial, la bibliografía citada en las pp. 421-422.

${ }^{41}$ Vid. E. Garcia de EnTERRIA: La revisión del sistema de Autonomías territoriales: reforma de Estatutos, leyes de transferencia y delegación, federalismo, Civitas, Madrid 1988. 
petencial. Con ello me refiero, en primer lugar, a la existencia de dos tipos de Comunidades: unas susceptibles de alcanzar el techo competencial previsto en la Constitución desde su formación, y otras con ese techo limitado por un periodo de cinco años, según establece el artículo 148-2 de la misma. En segundo lugar, a la problemática concreta que ambos tipos pueden plantear en la ulterior etapa.

Podría parecer que la primera clase de autonomías no deberían generar problemas en esta segunda fase; sin embargo, y no por casualidad, quizás sean las más conflictivas, debido a la complejísima regulación que el texto constitucional efectúa sobre la distribución de competencias, que ha supuesto multitud de conflictos en los años de vigencia ${ }^{42}$ : En el caso de las Comunidades del segundo tipo, es problemático tanto el procedimiento como las directrices para alcanzar el techo aludido, debido a la confusión existente sobre la reforma de los Estatutos. Es preciso tener presente también la existencia del principio de voluntariedad; con ello quiero decir que así como ha habido un acuerdo de los grandes partidos, de forma extraparlamentaria, sobre la confección del mapa autonómico, la cuestión no es tan sencilla a la hora de consumar la plena autonomia; no sólo debido a causas políticas sino estructurales y, sobre todo, de tipo económico, que pongan de manifiesto la innecesaria asunción de nuevas competencias por parte de alguna o algunas Comunidades Autónomas, para las que no se encuentran preparadas ni técnica ni financieramente.

Tampoco es despreciable el aprovechar la ocasión de plantearse la reforma de los Estatutos (sea cual sea la vía elegida) para efectuar otras modificaciones singulares de los mismos en aspectos puntuales en que la práctica haya señalado deficiencias subsanables, sobre todo en aquellas Comunidades cuyos Estatutos fueron producto del mimetismo, desde el punto de vista institucional ${ }^{43}$. Asimismo, ya con una jurisprudencia consolidada del Tribunal Constitucional, sería el momento de proceder a la homogeneización de criterios en cuanto a las relaciones Estado-Comunidad Autónoma, dada la presunta tendencia igualatoria a la que, en principio, estamos avocados. No es fácil, sin embargo, por la distinta genética de unos y otros entes territoriales, pues todo lo que no sea singularidad encontrará reticencias en las Comunidades históricas, con unos y otros matices. En mi opinión, cuando tales especificaciones se refieran a lo que constituye su singularidad ha de ser respetado, lo que no quiere decir que tal singularidad deba ser trasladada a ámbitos distintos, lo que supondría perjudicar el correcto funcionamiento y la necesaria coordinación entre el Estado y las Autonomias.

42 Vid. nota 39.

${ }^{43}$ Vid. F. J. Garcia Roca: Contribución al estudio de la forma territorial del Estado español, Universidad Complutense, Madrid 1985. 
En el momento de afrontar este hipotético fin del proceso nos encontramos, desde el punto de vista institucional, con una dificultad añadida. Ya se ha visto cómo no existe un instrumento de participación de las Comunidades Autónomas en la formación de la voluntad del Estado; ya se analizaron las razones tácitas o implícitas de tal carencia ${ }^{44}$. Por ello no es de extrañar que, en ámbitos diferentes, se formulen simultáneamente propuestas que faciliten la negociación, ya que no la aprobación, del hipotético final del proceso: la gestación de un nuevo pacto autonómico entre las fuerzas políticas más relevantes, la reforma del Reglamento del Senado e, incluso, la reforma constitucional.

\section{PROBLEMAS DERIVADOS DE UN HIPOTÉTICO FIN DEL PROCESO. LA SIMULTANEIDAD DE LA INTEGRACIÓN EN EUROPA}

Al llegar aquí surge la pregunta de si significará el fin del proceso el ampliar al máximo el techo autonómico de las distintas Comunidades, habiendo llegado a una hipotética igualación en el sentido expresado anteriormente. En principio pudiera contestarse afirmativamente ya que las previsiones constitucionales se habrian cumplido. Sin embargo, la cuestión no es tan clara, pues si bien técnicamente sería factible, razones de tipo politico y estructural hacen prever que, a lo máximo, se logrará un avance más en la homogeneización pero sin llegar a la misma, no ya entre las Comunidades históricas sino entre las demás.

Otra pregunta a formular sería si la ampliación competencial hasta el máximo previsto en la Constitución, supondría la modificación de la naturaleza de nuestro Estado autonómico. En su momento se rechazaron, por no adecuadas, la tripartición técnico-jurídica clásica sobre las formas de Estado, habiendo propuesto la de Estado compuesto como único modo de entender cabalmente la estructura de nuestro Estado. Si de lo que se trata, admitida la descentralización política, es de medir grados, no cabe la menor duda, al menos en principio, de que un mayor ámbito competencial de las entidades territoriales, implica un mayor grado de intensidad de la autonomía y entidad, aun como parte del Estado, de las Comunidades Autónomas. Pudiera parecer cuestión baladí; para mí no lo es porque entiendo que, en un Estado de democracia clásica u occidental, los poderes públicos están al servicio del ciudadano, y su ejercicio sobre éste, sobre todo los más próximos, constituye el elemento conformador de la idea que el ciudadano se forja sobre el poder; ello genera mentalidades y actitudes po- 
líticas que van a tener, a medio y largo plazo, a través del sufragio, repercusión en la evolución del Estado. Con todo, es pronto para aventurar cualquier tipo de juicio al respecto, pero creo importante tener presente la cuestión apuntada.

Otro punto de interés, quizá mayor, al llegar a esta ocasión histórica de reconducción de la configuración del Estado en el ámbito de la descentralización territorial, sería el tener en cuenta el hecho, también histórico, de estar inmerso en otro proceso, de idéntica naturaleza pero de signo contrario, al integrarnos en la Comunidad Europea ${ }^{45}$. No cabe duda que ambas dinámicas, de signo contrario, no pueden ser tratadas de manera separada sino como partes integrantes de un solo conjunto. El lograr la definición definitiva o cuasidefinitiva de la estructuración del poder territorial en nuestro Estado sin tener en cuenta el simultáneo y, de momento, acelerado proceso de integración europea como parte de un mismo problema, sólo puede llevar a planteamientos parciales que generen más conflictos de los que resuelvan o a no evitar, cuando menos, posibles problemas futuros. Es curioso que la doctrina, dependiendo del área de la que provenga (Derecho Constitucional, Derecho Administrativo, Derecho Internacional, Relaciones Internacionales, ...) insiste en los procesos abiertos en uno y otro ámbito pero, en cambio, se echa de menos una consideración simultánea de los mismos; ello perjudica sobremanera la visión del conjunto así como impide el prever soluciones, en uno y otro ámbito, que faciliten fórmulas coordinadas capaces de evitar malentendidos futuros.

En cualquiera de los casos, la integración de España en la Comunidad Europea, ha supuesto la realización de un traslado de competencias, tanto estatales como autonómicas, a los órganos de decisión comunitarios. Claro está que ello no tiene por qué suponer, en principio, la alteración de la distribución territorial del poder dentro del Estado; pero de la práctica producida en los Estados compuestos integrados en la Comunidad Europea, y más en concreto en Italia y Alemania, se ha generado un proceso de acumulación de poder en los Estados Centrales, en detrimento de los poderes propios de sus entidades territoriales ${ }^{46}$. Lo más curioso radica en que esta concentración, por la naturaleza del Derecho comunitario, no se ha producido de modo equilibrado entre los distintos órganos del Estado, sino que ha beneficiado sustancialmente a los Ejecutivos.

Un inconveniente añadido deriva de la imprecisión de las competencias comunitarias, que no constituyen un corpus cerrado sino sumamente abierto y flexible, lo que posibilita una creciente expansión según

45 M. Fraga Iribarne: “Los espacios regionales en el marco de la CEE», en su libro De Galicia a Europa, Planeta, Barcelona 1991, pp. 112 y ss.

46 Vid. S. MuÑoz MACHADO: El Estado, el Derecho interno y la Comunidad Europea, Civitas, Madrid 1986. En las pp. 291 y ss. incorpora una interesante bibliografía comentada. 
se vaya progresando en la integración europea. No cabe duda que los Estados, a través de los Ejecutivos, son los que adoptan las decisiones comunitarias; por ello, se podría hablar de doble proceso: ascendente (fase. de elaboración de las decisiones comunitarias) y descendente (fase de ejecución). No se trata aquí de pormenorizar en el estudio de esta problemática, pues no es el objeto del trabajo, pero sí de apuntar la complejidad de la cuestión y sus indiscutibles consecuencias sobre la distribución de competencias que efectúa nuestra Constitución.

Si nos detenemos en la llamada fase ascendente, cuyas competencias corresponden a los distintos Ejecutivos estatales, se echa de menos en nuestro sistema político la existencia de cauces formalizados, que permitan a las Comunidades Autónomas, como tales entidades territoriales, participar. A pesar de las previsiones de algunos Estatutos al respecto, artículo 20,3 del Estatuto Vasco, 23,2 del Estatuto de Andalucia, 37,1 del Canario y 27,4 del Catalán, los procedimientos para lograr la señalada participación, son ambiguos y no debidamente perfilados ${ }^{47}$.

No es de extrañar, por tanto, como veremos más adelante, que algunas fuerzas politicas, al plantearse la reforma del Reglamento del Senado, incorporen a sus propuestas previsiones a efecto de información y participación de las Comunidades Autónomas en la política exterior del Estado, y, en particular, en todo lo referente a la adopción y ejecución de medidas comunitarias que incidan en su ámbito competencial ${ }^{48}$.

\section{EL ESTADO DE LA CUESTIÓN EN EL MOMENTO ACTUAL}

En el momento presente, y teniendo en cuenta lo expuesto hasta aqui, nos encontramos en una situación eminentemente dinámica, que implica la adopción de una serie de decisiones encaminadas bien a poner fin al proceso que significan el artículo 2 y el Título VIII de la Constitución, bien a efectuar alguna remodelación que, al menos, suponga un avance sobre

47 A título de ejemplo, vid. J. Jiménez UGARTE: «El Ministerio de Asuntos Exteriores y la acción en el exterior de las Comunidades Autónomas", en Informe Pi i Sunyer sobre Comunidades Autónomas, Civitas, Barcelona 1990, pp. 240 y ss.; y J. ToRnos: «Disposiciones reglamentarias del Gobierno y de la Administración del Estado", en la misma obra citada, pp. 40 y ss., en lo que se refiere a subvenciones y aplicación del Derecho comunitario.

${ }_{48}$ Vid. Epígrafe VII. 
lo existente ${ }^{49}$. Claro está que no se puede menospreciar una actitud de pasividad ante la necesaria evolución del proceso; sin embargo, parece que la mera pasividad o estancamiento es prácticamente imposible, por varias razones:

- Porque la norma constitucional deja abierta la puerta a la ampliación de competencias en aquellas Comunidades Autónomas que no han alcanzado el máximo techo posible; la presión de estas entidades territoriales constituye un elemento de primer orden a tener en cuenta;

- porque las fuerzas políticas actuantes en estas Comunidades o en algunas de ellas, aun perteneciendo a partidos de implantación nacional, constituyen un elemento de presión sobre los mismos tendente a igual fin; ni que decir tiene las fuerzas políticas de signo nacionalista, así como los partidos regionalistas, aun con distintas perspectivas y finalidades ${ }^{50}$.

Así pues, la posiblidad de un estancamiento del statu quo actual, parece poco menos que imposible, ya que no lo desean ni las fuerzas políticas actuantes en el Estado ni aquellas que operan en el ámbito autonómico.

Desechado el estancamiento, son tres las alternativas que se pueden plantear respecto al fin del proceso. En primer lugar se podría señalar el intento de finalización, según las previsiones constitucionales, remodelando, a través de la reforma de los Estatutos, la vidriosa cuestión de la distribución de competencias. Una segunda hipótesis vendría determinada por la reforma constitucional, referida exclusivamente a este campo, en las dos cuestiones en que la norma adolece de lagunas e imprecisiones: en concreto, la insuficiente participación de las Comunidades Autónomas, como tales, en la formación de la voluntad estatal y el poner orden y claridad en la distribución competencial. Por último, la alternativa que de momento se está propugnando, consistirá en entender que con la reforma del Reglamento del Senado, se podrian paliar las deficiencias antedichas: participación de las Comunidades en la formación de la voluntad estatal y coor-

49 Vid. un análisis al respecto en E. Garcia de Enterria: La revisión del sistema de Autonomias territoriales: reforma de Estatutos, leyes de transferencia y delegación, federalismo, Civitas, Madrid 1988.

50 Las declaraciones de políticos autonómicos son reiterativas, con sentidos distintos, tanto de Comunidades históricas como de las que, en su día, se acogieron al articulo 143 de la Constitución; así lo pusieron de relieve las elecciones municipales y autonómicas de mayo de 1991. Como ejemplo, ver las declaraciones del presidente del Gobierno Autonómico de Aragón al diario El Sol, el 2 de agosto de 1991. 
dinación entre Estado y Autonomías en el ámbito competencial. A continuación se examinarán cada una de estas alternativas.

\section{A. Reforma de los Estatutos}

El proceder mecánicamente a completar el techo autonómico de aquellas Autonomías que accedieron a su autogobierno a través del artículo 151 de la Constitución, no deja de plantear problemas concretos ${ }^{51}$; es posible que cada Comunidad Autónoma, en ejercicio del principio de voluntariedad y en función de su situación real, intente dar un paso más en el ámbito competencial, pero sin pretender llegar al máximo posible. Por otra parte, también las Comunidades históricas intentarán, aun en el supuesto de llegar a la homogeneización de las demás Comunidades, ampliar sus competencias, si bien no en el ámbito legislativo -más o menos definidas por la jurisprudencia del Tribunal Constitucional-si en el ámbito de su ejecución. En cualquiera de los casos son dos las posibilidades que se pueden plantear desde una perspectiva global, pese a las dificultades señaladas: o bien se procede a un criterio de igualación, lo que, al menos desde el punto de vista competencial, nos acercaría en gran medida a la federalización material, o bien se procede al establecimiento de un sistema desigual, que no pondria fin al proceso en este ámbito, al menos sobre máximos, dejando abierta la puerta a ulteriores remodelaciones al alza, en aquellas Comunidades que no hubieran alcanzado el techo.

En cualquiera de los casos, la finalización o cuasifinalización de este proceso, exige una ardua labor de entendimiento entre las fuerzas políticas y las Comunidades Autónomas, y ello, claro está, desde una perspectiva extraparlamentaria, desde el momento en que no existe institución estatal en la que se puedan debatir tales extremos. Ningún Gobierno se atrevería a plantear en el Parlamento tan grave y decisiva cuestión, bien a través de la reforma de los Estatutos bien mediante Ley Orgánica, sin que previamente hubiera sido pactado, hasta en sus mínimos detalles, la remodelación del ámbito competencial.

51 No se plantea aquí la cuestión del procedimiento a seguir en cuanto al medio técnico-jurídico a través del cual se puede proceder a la ampliación del nivel competencial, en las Comunidades que accedieron a la autonomía según el artículo 143 de la Constitución. Las posibilidades, sustancialmente, serían dos: la reforma de los Estatutos o de las Leyes previstas en el artículo 150,2 de la Constitución; respecto a esta problemática, vid. E. GARCÍA de ENTERRÍA, op. cit. 


\section{B. Reforma de la Constitución}

La carencia de ese foro institucional ha generado algunas opiniones favorables a la reforma del texto constitucional ${ }^{52}$, a fin de convertir al Senado en una auténtica Cámara de representación territorial. Esta posibilidad ya fue apuntada en la doctrina en los primeros momentos de vigencia constitucional; así, por ejemplo, LEGUINA VILLA, al tratar de definir nuestro Estado, lo denomina Estado unitario regionalizable, señalando que el sistema establecido por la Constitución en lo referente al Senado, es «un sistema hibrido, con notorio predominio del escalón provincial sobre el escalón nacional o regional, que todo parece indicar ha sido adoptado como una solución rigurosamente provisional hasta tanto se regionalice plenamente el Estado, momento en el que con toda probabilidad habrá de acometerse la necesaria reforma de la composición del Senado» ${ }^{53}$.

En cambio, en el momento presente, la reforma de la Constitución ha sido mayoritariamente desechada, por los riesgos que implica; riesgos que podrían reconducirse exclusivamente a uno, aunque multiforme: la dificultad politica de establecer el ámbito de tal reforma, una vez iniciado el procedimiento ${ }^{54}$. Después de trece años de vigencia constitucional, la práctica ha puesto de relieve la insuficiencia u oscuridad de muchas de sus disposiciones, sumamente discutidas. Iniciar la modificación constitucional traeria como consecuencia, de modo inevitable, el que cuestiones muy puntuales y controvertidas fueran también objeto de solicitud de revisión; me refiero a necesidades de reforma más políticas que técnicas, pues éstas ya han sido puestas de relieve por la doctrina en múltiples campos; plan-

52 Vid. Epigrafe VI.

53 «Las Comunidades Autónomas», en A. Predieri y E. Garcia de Enterria: La Constitución española de 1978. Estudio sistemático, Civitas, Madrid 1980, p. 750.

${ }_{54}$ La apertura de un debate al respecto, pondria de relieve sus dificultades; cuestión distinta es el que se pueda llegar a acuerdos muy puntuales. Así, como veremos más adelante, la propuesta de reforma del Reglamento del Senado, hecha por el Grupo Parlamentario Vasco (PNV), no ve dificultad alguna en la reforma de la Constitución para hacer al Senado auténtica Cámara autonómica, ya que sólo requeriria el procedimiento simple previsto en el articulo 167 de la Constitución, que no exige disolución de las Cámaras. En cambio, en mi opinión, la cuestión es más ardua, porque una potenciación constitucional del Senado afecta a otros órganos constitucionales y sería preciso lograr un consenso, sobre todos los aspectos y matices, en relación a cuál seria el resultado final, en cuanto a su incidencia dentro del sistema constitucional y político. En todo sistema, entendiendo por tal «un todo relacional en el que cada una de las partes ocupa el lugar que le corresponde y no otro", cualquier variación en alguno de sus elementos repercute en todo el sistema y, en consecuencia, es necesario tener previstas estas repercusiones a efecto de lograr el fin deseado y no otro. 
teamientos muy diversos incorporados al texto por mor del consenso, no podian llevar a otra situación.

Aun en la hipótesis de circunscribir la reforma constitucional al mero ámbito del Senado, adecuando el desarrollo de su regulación a lo que la propia Constitución establece en el artículo 69-1 («El Senado es la Cámara de representación territorial»), pone en tela de juicio otros muchos aspectos, $v$. gr., ¿es posible seguir manteniendo la representación en el Senado con base provincial e insular?, ¿bastaria con trasladar a las Comunidades Autónomas el cupo de representación que actualmente les corresponde por su territorio?, ¿estarian de acuerdo las fuerzas políticas en mantener el sistema electoral?, ¿bastaria el criterio de compensación, según el número de habitantes, que se contempla en el texto actual?; y, lo que es más importante, admitiendo que el Senado sea Cámara de representación territorial y se instrumenten los medios suficientes y eficaces para ello, ¿con qué naturaleza?, pues bien podría ser una Cámara que representase a la población de las Comunidades como tales o bien una Cámara en la que estuvieran representados los gobiernos autónomos ${ }^{55}$.

En ambos casos, existe una cuestión de principio que es necesario dilucidar a priori: aunque hayamos rechazado la idea de la tripartición clásica por inadecuada a nuestro actual sistema político - Estado unitario, federal o regional - al fin de este proceso tendríamos un dato sustancial para aproximarnos a su calificación; y ello porque si se admite que la segunda Cámara territorial es el ámbito de participación de las Comunidades Autónomas en la formación de la voluntad estatal, nos habríamos acercado de modo notorio a una federalización, pues en el fondo no se trata más que de reconocer la entidad política que supone la Comunidad Autónoma como un grupo singularizado, con intereses, fines y proyectos propios, sin tener en cuenta - al menos en esta fase del proceso- los intereses generales de la Comunidad estatal en que se integran.

Otra cuestión distinta derivaria de un planteamiento menos radical, que se reduciría a desvincular la representación de los grupos ideológicos dominantes. Fácilmente se entenderá que, tanto en el supuesto de representación de la población autonómica como de los gobiernos autónomos, se estaría pidiendo a los partidos políticos mayoritarios la renuncia a un statu quo institucional que, de futuro, pondría en duda su dominio en la segunda Cámara.

${ }^{55}$ Aceptado el principio de representatividad del Senado como Cámara de las Comunidades Autónomas, habría que añadir la cuestión de la igualdad o desigualdad entre éstas; ver al respecto, en el Epígrafe VII, las propuestas de Convergència i Unió y Nacionalistas Vascos, en las que se barajan ambos criterios: proporcionalidad e igualdad. 
Por último, y sin afán de exhaustividad, es necesario tener presente que se podrían banalizar los problemas aludidos, dado que la Constitución establece un claro predominio del Congreso de los Diputados y que los riesgos señalados serían de fácil solución institucionalmente, pero no se puede olvidar que si se inicia la reforma también se podrian modificar los ámbitos competenciales de Congreso y Senado. Si se sigue el modelo alemán, habría que especializar al Senado como Cámara territorial y en este ámbito; es decir, en aquellas cuestiones directamente relacionadas con las Comunidades Autónomas. Aqui nos volveriamos a encontrar con otro problema: si se acudiria a una federalización igual o desigual; $y$ en el segundo caso, cuál sería el criterio aplicable.

Todo to dicho no ha sido más que una reflexión respecto a una problemática que, con mayor o menor énfasis, han percibido las fuerzas políticas, tanto nacionales como autonómicas, sobre todo en las Comunidades históricas. Creo que son muchas las alternativas y, en consecuencia, los puntos a debatir y acordar antes de proceder al siempre complejo mecanismo de reforma; como veremos más adelante, determinadas fuerzas políticas solicitan la reforma constitucional, pero con un significado tan distinto, que manifiesta que en la actual situación se encuentra abierto el debate pero sin criterios claros que pudieran hacer progresar la reforma con visos de éxito.

\section{Reforma del Reglamento del Senado}

La imposibilidad política del estancamiento, en esta fase de la descentralización, y las dificultades significativas que conlleva la reforma constitucional, ha llevado al Gobierno, con cierto apoyo doctrinal, a intentar finalizar el proceso a través de la reforma del Reglamento del Senado.

El Gobierno, con un consenso de las fuerzas políticas, ha aceptado esta solución y, aun con muchos matices, se ha podido llegar a una formulación parlamentaria, a través de la Ponencia de la Comisión de Reglamento del Senado. En la sesión de 25 de abril de 1990 se adoptó un acuerdo tendente a iniciar el procedimiento parlamentario sobre reforma del Reglamento, que permita la territorialización de la Cámara.

Antes de examinar las propuestas de los grupos parlamentarios, que van a dar lugar al acuerdo de 25 de abril de 1990, ya señalado, considero 
necesario recordar el marco institucional en el que operan ${ }^{56}$. Ya se ha visto cómo, en la regulación constitucional, el Senado se encuentra subordinado al Congreso; es decir, se encuentra limitado en sus competencias desiguales ad minor respecto a la otra Cámara. Casi se podría afirmar que sus atribuciones, en paralelo con el Congreso, y aunque sean de naturaleza territorial son mínimas ${ }^{57}$. Pero, por si ello fuera poco, el actual Reglamento del Senado aún las reduce más, desde el punto de vista operativo; así, los denominados grupos territoriales han sido regulados de modo limitativo y, como se ha llegado a decir, con un carácter hostil. Esta situación de indigencia se manifiesta en varios aspectos, que pueden reducirse a cinco:

a) El artículo 27-1 del Reglamento exige un número de diez senadores para la creación de un grupo parlamentario, esto impide la creación de un grupo territorial, si tenemos en cuenta el sistema de elección y el modo de designación de los componentes del Senado desde el punto de vista territorial.

b) Si lo que se pretendió fue el fraccionamiento de las fuerzas políticas en la organización interna de la Cámara, el número establecido es realmente inoperante; por si fuera poco, el artículo 27-3 impide a las formaciones que hayan concurrido a las elecciones formando parte de un mismo partido, federación, coalición o agrupación electoral, integrarse en más de un grupo parlamentario, con lo que se evita a quienes se integren en un grupo ideológico, crear un grupo territorial.

c) Por tanto, la admisión de grupos territoriales ha de efectuarse dentro de los grupos parlamentarios, con todas sus consecuencias.

d) A esta evidente y obvia limitación a la formación de grupos parlamentarios de naturaleza territorial, ha de añadirse el escaso número de competencias que pueden desempeñar los grupos territoriales en el procedimiento parlamentario, estando mediatizados en su ejercicio, además, por la intervención del grupo parlamentario.

56 Entre otros, vid. para este tema: E. AJA: «Por un Senado de las nacionalidades y regiones», en G. TRUJILLo (comp.): «Federalismo y regionalismo», CEC, Madrid 1979; E. AJA y X. ARBos: «El Senado, Cámara posible de las Autonomias», REP, núm. 17, 1980; F. FERnÁndez SEgADo: "La funcionalidad del Senado en cuanto Cámara de representación territorial», Revista Vasca de Administración Pública, núm. 13, Oñate 1985; P. Garcia-Escudero y B. PendAs: «El Senado en el sistema constitucional español. Realidades y perspectivas», RCG, núm. 1, 1984; X. PIBERNAT DOMENECH: El Senado en la Constitución española de 1978, Universidad Autónoma, Barcelona 1984; R. PUNSET BLANCO: “El Senado en la nueva Constitución española», RFDUC, núm. 57, 1979.

57 Vid. J.M. Morales Arrovo: "Notas en torno a la reforma del régimen jurídico del Senado español», en La Ley, núm. 3, 1989, p. 954. 
e) Las competencias de los grupos territoriales son las previstas, con carácter de numerus clausus, en los articulos 32-3 y 137-3 del Reglamento; no cabe, con la actual regulación en las manos, una interpretación extensiva de sus atribuciones; para ellos no existen poderes implícitos o resultantes.

En resumen, los grupos territoriales son ancillares de los grupos parlamentarios; éstos ostentan el protagonismo político y, sólo con su consentimiento, podrán tener una exigua participación los grupos territoriales constituidos. La práctica parlamentaria existente hasta el momento, es relevante en este sentido. Ante esta situación no es de extrañar que sea legítimo empezar por donde se debe empezar; es decir, por el principio. No se trata de discutir la insuficiencia notoria de la regulación constitucional, sino de señalar que esa insuficiencia ha continuado en el desarrollo interno del funcionamiento del Senado: no sólo limitando sino, incluso, excluyendo la posibilidad de territorialización del mismo ${ }^{58}$.

Parece lógico, en consecuencia, no desdeñar una iniciativa de esta naturaleza; de ahí el interés que tienen, a mi entender, las propuestas efectuadas por todos los grupos parlamentarios, así como el consenso iniciado en el procedimiento. Desde luego no van a resolver el problema de fondo, desde un punto de vista constitucional, pero pueden sentar las bases para una evolución positiva y favorable respecto a la construcción de un auténtico Estado de las autonomias; posibilitarán que los pasos formales posteriores estén fundamentados en un debate previo, profundo y pactado.

\section{ANÁLISIS DE LAS PROPUESTAS DE REFORMA DEL REGLAMENTO DEL SENADO}

\section{A. Cuestiones previas}

Ya se ha visto ${ }^{59}$ la posición jurídico constitucional en la que se encuentra el Senado en nuestro ordenamiento; pese a su definición como

58 A la hora de comprender el origen de una regulación tan restrictiva, baste con pensar la fecha de discusión y aprobación del Reglamento, fecha en la que aún no se había diseñado el mapa autonómico, con lo que el fundamento del misno no es sino el de una segunda Cámara de representación ideológica.

${ }_{59}$ Vid. Epígrafe II. 
Cámara territorial, en su momento se puso de relieve su naturaleza de Cámara de segunda lectura, que obedece tanto a razones de tipo estructural como funcional. Considero que no es preciso repetir que, desde el punto de vista funcional (arts. 155, 150-3, 145, 158, 168) las competencias del Senado son secundarias respecto al Congreso, normalmente deben ser ejercidas en un breve lapso de tiempo y sus decisiones, salvo los casos previstos en los artículos 153, 155 y 158, pueden ser revocadas por la Cámara Baja, incluso en aspectos tan decisivos para las Comunidades Autónomas como la reforma de sus Estatutos, el supuesto del articulo 149 amén de los previstos en el artículo 150. Si es claro el carácter ancillar del Senado respecto del Congreso, hay que añadir que esta Cámara no representa a las Comunidades Autónomas, pues en la realidad actual y desarrolladas las previsiones constitucionales, solamente son designados por ésta una quinta parte de los senadores; el resto son elegidos por las provincias y las islas.

Desde un punto de vista operativo, la práctica parlamentaria ha demostrado que, ideológicamente, el Senado es un duplicado del Congreso, en contra de algunas previsiones de los Constituyentes ${ }^{60}$; pero es que además, desde el punto de vista organizativo interno de la Cámara, como ya se ha señalado, los grupos territoriales son inoperantes debido a su dependencia de los grupos ideológicos.

Desde una perspectiva estrictamente política, tampoco los senadores tienen el personal más adecuado para una Asamblea que pretende realizar una representación territorial; los senadores se caracterizan por su menor relevancia política y técnica y así lo demuestra la ausencia de líderes políticos de la Cámara Alta. De ahí deriva el que su actuación no suscite entusiasmo e, incluso, interés en la opinión pública; tampoco han contribuido los gobiernos sucesivos a eliminar o aminorar esta idea ${ }^{61}$.

En consecuencia, ni la configuración jurídico constitucional, ni su desarrollo reglamentario, ni siquiera la práctica política, han contribuido a situar al Senado en la posición de Cámara territorial señalada en el artículo 69-1 de la Constitución. Hasta ahora la Cámara Alta solamente ha servido para corregir proyectos o proposiciones de ley que adolecian de vicios de constitucionalidad, así como de errores técnicos o inoportunidad política. Siguiendo en este terreno de la práctica, el Senado también ha sido aprovechado para llevar a buen término proyectos legislativos sobre los que no se había logrado el acuerdo deseado en otros ámbitos. Ahora bien, tales

60 Vid. el análisis efectuado por F. Fernandez Segado: «La construcción del Senado en el proceso constituyente", $R E P$, núm. 38, 1984; sobre las consecuencias de la enmienda del diputado Alzaga en la Comisión Constitucional del Congreso.

${ }^{61}$ Después de trece años, el problema de la estructura del Senado ya no es sólo una cuestión de definición de un Órgano, sino de la existencia de una pieza fundamental que necesita el sistema político para su congruencia. 
actuaciones no legitiman lo que hasta hoy ha constituido la funcionalidad del Senado en la práctica de nuestro sistema político.

Por todo lo dicho, la pretensión de potenciar el papel del Senado sólo será significativa si se centra en la definición constitucional del artículo 69-1 como Cámara territorial. Con anterioridad ${ }^{62}$ se ha hablado de que en el esquema de un Estado compuesto, la Cámara territorial incide en dos de sus relaciones típicas, las de coordinación e inordinación, así como la insuficiencia con que se regulan ambas en nuestra Constitución; en consecuencia, si de algún modo se quiere potenciar el Senado, sólo es posible en esta línea.

Sin embargo, convertir al Senado en una auténtica Cámara representativa de las autonomías, no es tarea fácil, pues nos encontramos con la necesidad, en sentido jurídico estricto, de reformar la Constitución, dada la configuración que en la misma se le ha dado. Con todo, el intento de agotar las vías para lograr la territorialización, dentro de los límites impuestos, no deja de ser loable y posible, en tanto en cuanto obedezcan a un auténtico pacto político respecto lo que haya de ser el Senado en el futuro; si ese pacto se logra, puede servir para abrir caminos que faciliten la coordinación e inordinación del Estado y las Comunidades Autónomas.

\section{B. Delimitación del tema}

Descartada la reforma constitucional a efecto de potenciar el papel del Senado en nuestro sistema político, las distintas fuerzas parlamentarias se han centrado de modo unánime en su revitalización y, como luego se verá, existen bajo distintas ópticas, diversos modos de realizarlo, con un solo punto coincidente: convertir al Senado en Cámara de representación territorial a través de la reforma de su Reglamento.

Esta cuestión se plantea esencialmente, desde el punto de vista procedimental, ante la Ponencia de la Comisión de Reglamento, por iniciativa del partido del Gobierno, con la idea de propugnar el carácter territorial de la Cámara. Los distintos grupos parlamentarios del Senado incluyen en sus propuestas, junto a las medidas tendentes a la territorialización, otras cuestiones que afectan in genere a un mayor protagonismo de otra naturaleza; se han desechado estas sugerencias para centrarse exclusivamente en el análisis de todo aquello que pueda servir a la territorialización de la institución. Este examen puede aportar las posiciones reales de los partidos, 
su pensar y sentir, aunque sólo en este punto, respecto de la consideración transitoria, o, en su caso, final, del Estado de las autonomías.

\section{Cuestiones procedimentales ${ }^{63}$}

Las propuestas efectuadas por los grupos parlamentarios obedecen a una etapa inicial de acuerdo político entre las distintas fuerzas de la Cámara, tendente a la reforma del Reglamento; ello se deduce del hecho cierto de que los grupos parlamentarios socialistas (18 abril 1990), mixto (Iniciativa per Catalunya-Izquierda Unida) (22 marzo 1990) y nacionalistas vascos (26 marzo 1990), dirigen su escrito al presidente de la Comisión de Reglamento, mientras Convergència i Unió (26 marzo 1990), Centro Democrático y Social (26 marzo 1990) y Popular (22 marzo 1990) al presidente del Senado. Todas estas propuestas serán remitidas, como es obvio a la Comisión de Reglamento, prevista en el artículo 49-2 in fine de esta norma. Desde esta instancia se les da traslado a la Ponencia de la misma quien, en su reunión de 25 de abril de 1990, adopta un acuerdo al respecto, sobre el que volveremos más adelante. Posteriormente, el Grupo Mixto envía un escrito el 8 de mayo de 1990, solicitando se incorpore al anteproyecto de reforma la institucionalización y reglamentación del debate sobre las Autonomías, con periodicidad anual y participación del presidente del Gobierno; a su vez, el Grupo Popular, el 30 de octubre de este mismo año, remite a la Comisión un proyecto articulado de adaptación de las propuestas de los distintos grupos al señalado acuerdo de la Ponencia de 25 de abril. Por último, con fecha 19 de febrero de 1991, se añade un nuevo apartado al inicial acuerdo de la Ponencia de 25 de abril de 1990, por el que se admite la posibilidad de incorporar a los trabajos parlamentarios del Senado, la utilización de otras lenguas oficiales, aparte del castellano.

Dicho lo anterior, parece adecuado el proceder a un análisis individualizado de cada una de las propuestas y a continuación un examen del Acuerdo de la Ponencia de 25 de abril de 1990.

\section{Propuestas de los grupos parlamentarios}

Como ya se indicó, adquiere una importancia sustancial la opinión adoptada por cada grupo parlamentario sobre la territorialización del Sena-

63 La documentación utilizada a partir de aquí es inédita. El principio de publicidad de los trabajos parlamentarios es la base para su uso; vid. el Título $X$ del Reglamento del Senado. Cada uno de los documentos presentados tienen la fecha de entrada en la Comisión de Reglamento del Senado. 
do; con ello se va a señalar, no sólo el criterio de cada grupo respecto a la misma, sino también lo que significa la idea de territorialización para cada fuerza politica. Si bien no se pretende sacar conclusiones generales, sí muy indicativas respecto de las opiniones partidistas en fecha tan reciente.

1. Propuesta del Grupo Parlamentario Socialista para la reforma del Reglamento del Senado (18 abril 1990)

Esta propuesta parte de la madurez del sistema parlamentario español, así como de la exigencia de un desarrollo equilibrado del Estado Autonómico, que aconseja potenciar la función territorial del Senado. Considerando el carácter abierto de la Constitución y la formulación realizada por su artículo 69-1, se entiende necesario precisar el carácter territorial del Senado respecto a la designación de senadores por las Asambleas Parlamentarias de las Comunidades Autónomas, así como el contenido del artículo 155 de la Constitución en lo que se refiere al requerimiento a aquéllas del cumplimiento de sus obligaciones constitucionales y legales.

Este grupo parlamentario considera que la situación actual sugiere la conveniencia de que el Senado sirva como foro permanente de encuentro entre la Administración central y autonómica, en un doble sentido: formación de la voluntad estatal conjunta y canalización constructiva de los acuerdos y discrepancias que se susciten en la vida política cotidiana.

Se hace referencia a la introducción de usos parlamentarios consensuados, que permitan la participación de miembros de los Consejos de Gobierno de las Autonomías en la preparación y desarrollo de sus debates; en esta línea de generación de usos parlamentarios se manifiesta la necesidad de participación de representantes de las instituciones autonómicas en las Comisiones de Autonomia, Organización y Administración Territorial y Seguimiento del Fondo de Compensación Interterritorial; la consolidación y ampliación de tales usos, sobre lo que existe opinión coincidente del resto de los grupos parlamentarios, supondría un avance significativo en la territorialización del Senado.

El Grupo Parlamentario Socialista concluye su propuesta con la posibilidad de que los distintos grupos suscriban un acuerdo inicial básico fundamentado en seis puntos (que van a coincidir con el Acuerdo de la Ponencia de 25 de abril de 1990), tramitado ante la Ponencia de la Comisión de Reglamento, constituida por los portavoces de todos los grupos parlamentarios, para su posterior precisión y desarrollo; sin este imprescindible consenso, no existirian las condiciones políticas necesarias para abordar la reforma del Senado. 
2. Proyecto de territorialización del Senado del Grupo Popular (22 marzo de 1990)

La propuesta del Grupo Popular parte de la necesaria presencia de las Comunidades Autónomas en el Senado. Para ello propone lo siguiente:

a) La comparecencia - a petición propia- de los presidentes Autonómicos en el Pleno y en las Comisiones; la presencia de los presidentes de las Comunidades Autónomas en el Pleno, así como presencia y participación de los citados presidentes en la Comisiones de Autonomía y de Seguimiento del Fondo de Compensación Interterritorial.

b) El reforzamiento de la Comisión de Autonomías, aumentando considerablemente el número de miembros y arbitrando una configuración de la misma "que permita que esté constituida exclusivamente o en su mayor parte por los senadores designados por la Comunidades Autónomas según el artículo 69,5 de la Constitución». Se mantendrian las competencias actuales pero se añadirian otras nuevas: la posibilidad de articulación de la voluntad de las Comunidades Autónomas, a través del Gobierno, ante los órganos de las Comisiones Europeas; lograr, mediante esta Comisión, que el Senado pueda desempeñar «el papel de fuente de información para las Comunidades Autónomas de cuantos proyectos de todo tipo puedan afectar a sus intereses y que se tramiten ante los organismos de las Comunidades Europeas»; por último, sugiere que se «establezca el oportuno procedimiento reglamentario para que cuando una Comunidad Autónoma entienda que una determinada cuestión que afecta a sus intereses, deba ser considerada por los organismos de la Comunidad Europea, pueda plantearla ante esta Comisión, con objeto de que, previa deliberación, pueda adoptar en su caso la correspondiente moción favorable, de la que se daría cuenta inmediata al Gobierno así como a la propia Comunidad Autónoma peticionaria».

c) La creación de Comisiones territoriales, una por cada Comunidad Autónoma, para posibilitar la "emisión de criterio». Cada una de estas Comisiones quedaria integrada, automáticamente al inicio de cada legislatura, por todos los senadores elegidos en el territorio de la Comunidad Autónoma correspondiente, asi como por los designados por las mismas; en cada Comisión, al constituirse, se elegiria, entre sus miembros, a un presidente y un secretario, como minimo.

En cuanto a sus funciones, es sustancial lo que la propuesta denomina "emisión de criterio territorial" sobre los proyectos y proposiciones de ley que les efecten; asimismo se establecen procedimientos para la 
tramitación de dicha emisión de criterio, el cual «posibilitaría la auténtica territorialización del Senado, ya que gracias a este sistema se podrían patentizar en la Cámara de forma complementaria las necesidades, reivindicaciones, posiciones y puntos de vista de las Comunidades Autónomas sobre aquellos asuntos de carácter legislativo que directamente les afecten, sin perjuicio del criterio básico de los órganos de Gobierno propios de las mismas».

Estas Comisiones no perturbarian las funciones de las Comisiones Legislativas, ni mermarian las competencias que el Reglamento actual confiere a la Comisión de Autonomías, puesto que se trataria de proporcionar criterios a tener en cuenta por aquéllas a la hora de elaborar un dictamen sobre un proyecto o proposición de ley, lográndose de este modo que en la Cámara operasen simultáneamente el principio político y el principio territorial. Por otro lado, no complicarian el procedimiento actual ya que las Comisiones territoriales sólo serian operativas en caso de entrada en el Senado de proyectos o proposiciones de ley que afectasen a intereses de las Comunidades Autónomas.

d) La potenciación de los grupos territoriales, por dos razones: fortalecerian el carácter territorial del Senado y desempeñarian funciones complementarias de las realizadas por las Comisiones territoriales propugnadas. Para ello se propicia la ampliación de sus actuales competencias, en lo que se refiere a la asistencia a la Junta de Portavoces y a consumir turno en el Pleno en el que se debatan cuestiones que afecten de modo especial a su Comunidad Autónoma. Estas facultades deben completarse con la posibilidad de que tales grupos intervengan activamente en la vida del Senado, como tales grupos territoriales, tanto en el procedimiento legislativo como en el control del Gobierno.

\section{Propuesta de reforma del Reglamento del Senado del Grupo}

Parlamentario Centro Democrático y Social (26 de marzo de 1990)

La propuesta que contemplamos no se reduce al ámbito territorial, sino que afecta también al régimen de debates, a las deficiencias en los medios de control, a la regulación del procedimiento legislativo, etc.; se ocupa, pues, sólo parcialmente de la función territorial del Senado. En consecuencia, postula que la reforma debería operar en dos direcciones potenciadoras de la institución: como Cámara de segunda lectura y como Cámara territorial.

Este grupo parlamentario descarta expresamente la reforma de la Constitución y propugna llegar a acuerdos políticos y a modificaciones legislativas a fin de obtener un desarrollo pleno de la definición constitucional 
de la Cámara. Para el logro de estos fines, en lo que afecta a los aspectos territoriales, la propuesta se sustanciaría en los puntos siguientes:

a) Dado que el Gobierno no es responsable ante el Senado, es factible la elección diferenciada en el tiempo respecto al Congreso, con el fin de ligar las elecciones al Senado con las autonómicas y municipales, al menos en las Autonomias que accedieron a través del artículo 143.

b) Regular, con mayor fidelidad a la Constitución, la intervención del Senado en la distribución del Fondo de Compensación Interterritorial.

c) Posibilitar la audiencia de las Comunidades Autónomas, Corporaciones Locales y Comisiones especializadas del Senado en el procedimiento de elaboración de anteproyectos de ley y de reglamentos, al menos en aquellos de carácter territorial.

d) Atribución a alguno o algunos de los órganos de la Cámara la competencia de calificar como territoriales los proyectos de ley o de reglamentos.

e) Establecimiento de un mecanismo consensuado que permita «a las Comunidades Autónomas, de un lado, tener presencia en las delegaciones españolas ante las Comunidades Europeas, y del otro, tener participación en el diseño de la norma y medidas de adaptación o ejecución del Derecho Comunitario, al menos en el área de su respectivo interés".

f) A fin de lograr la especialización del Senado, se precisa lograr un acuerdo político en virtud del cual queden reservadas al Senado, como regla general, las comisiones de investigación y estudio, o, en su caso, constituir comisiones mixtas.

En cuanto al contenido concreto de la reforma, referida a la función territorial del Senado que establece la Constitución, se considera que «el Senado como Cámara de representación territorial debe operar como órgano de encuentro entre el Poder Central, Comunidades Autónomas y Poderes Locales"; para ello sería necesario:

«Primero.-Dar un papel de mayor relevancia al Senado en la deliberación de las leyes territoriales, definidas y calificadas como más arriba se ha señalado. 
Segundo.-Potenciar el papel de los senadores designados por las Comunidades Autónomas como nexo de unión entre todos los Parlamentos del Estado.

Tercero.-Utilizar en el mismo sentido las Comisiones especializadas de la Cámara.

Cuarto.-Centralizar en el Senado el registro de todos los instrumentos de colaboración y coordinación entre el Estado y las Comunidades Autónomas de un lado y de las mismas Comunidades entre si.

Quinto.-Reformar la composición de las Comisiones especializadas de la Cámara, a fin de facilitar la colaboración en los trabajos de las mismas de representantes de las Comunidades Autónomas y de los Poderes Locales.

Sexto.-Establecer la celebración anual de un debate sobre el Estado de las Autonomías.

Séptimo.-Establecer un procedimiento para que los presidentes de las Comunidades Autónomas puedan remitir al Pleno o a las Comisiones del Senado comunicaciones e informes para sus debates, en términos similares a los que dispone el actual artículo $182 \mathrm{del}$ Reglamento de la Cámara.

Octavo.-Modificar el régimen de propuestas de los miembros de órganos constitucionales o con relevancia constitucional que competen al Senado de tal modo que él mismo incluya como trámite necesario la participación de representantes de las Comunidades Autónomas".

4. Borrador de propuesta de reforma del Reglamento del Senado en relación con la Comisión de Comunidades Autónomas del Grupo Parlamentario Mixto (Iniciativa per Catalunya-Izquierda Unida) (22 de marzo de 1990)

Entiende el escrito en su preámbulo, la inexcusable necesidad de reforma constitucional, en lo que se refiere a la elección, composición y competencias del Senado, para convertirse en auténtica Cámara de representación territorial. La reforma del Reglamento sólo puede entenderse como un primer paso; para ello considera imprescindible la creación de lo que denomina «Comisión de Comunidades Autónomas».

Acompaña a la propuesta un texto articulado en el que se contienen la composición, funciones y otros aspectos de la citada Comisión, que sería 
permanente y no legislativa. Estaría compuesta por los senadores designados por las Comunidades Autónomas conforme al artículo 69-5 de la Constitución, y en ella podrían participar los presidentes de las distintas Autonomías, asi como los presidentes de sus Asambleas legislativas, con voz pero sin voto, previéndose sus sustitución por un consejero o vicepresidente, respectivamente.

En cuanto a las funciones, la citada Comisión deberá emitir dictamen preceptivo sobre la incidencia en el ámbito autonómico de cada uno de los proyectos o proposiciones de ley que tramiten las Cortes Generales, señalando, en su caso, si se produce invasión de competencias. Se establecen, a continuación, normas procedimentales internas.

Esta Comisión tendrá el carácter del permanente, no legislativa, con el fin de poder realizar encuestas o estudios sobre todas aquellas materias que estimen con incidencia autonómica. Por último, se propone que en tal Comisión puedan ser utilizadas, oralmente y por escrito, todas las lenguas que tengan el carácter de oficiales en alguna Autonomia. Como ya se dijo, el 8 de mayo de 1990 se amplió la propuesta incorporando la petición de institucionalizar y reglamentar el debate sobre las Autonomías, con periodicidad anual y participación del presidente del Gobierno.

5. Propuesta para la reforma del Reglamento del Senado, orientada a la consolidación de su carácter de Cámara territorial, del Grupo Parlamentario Convergència i Unió (26 de marzo de 1990)

En el preámbulo, este grupo parlamentario parte de la necesidad de acometer la reforma de la Constitución, pues «los límites que en ésta se imponen al funcionamiento de la Cámara Alta, impiden que por la única vía de la reforma de su Reglamento puedan alcanzarse cambios sustanciales en orden a lo que hasta ahora viene siendo en la práctica la vida del Senado». Se propicia la definición del Senado como institución «a través de la cual, las Comunidades Autónomas cooperan en la legislación y en el control de la Administración del Estado, al estilo de lo que representa el Bundesrat alemán, aunque ello implicaría la reforma de la Constitución..., reforma que no debe descartarse y que no comporta ningún riesgo para la estabilidad político institucional del sistema democrático español. Pero que asimismo no requiere de ninguna decisión urgente por cuanto conviene afrontarlo en el momento en que políticamente parezca más oportuno».

En consecuencia con lo dicho, para este grupo parlamentario, la reforma del Reglamento del Senado «debe tender más a los aspectos simbólicos que a un cambio en la naturaleza intrínseca del mismo»; ir más allá en la reforma del Reglamento, sin reformar la Constitución «podría contribuir a un reforzamiento contradictorio del Senado como Cámara ideológica, 
no territorial; es decir, atribuir decisiones al Senado en temas que afecten a las Comunidades Autónomas sobre la base de mayorías políticas, podria perjudicar sensiblemente los intereses y derechos de dichas Comunidades". puntos:

De acuerdo con lo dicho, la propuesta se centra en los siguientes

a) Los grupos parlamentarios del Senado han de ser territoriales, tantos como Comunidades Autónomas, manteniendo la libertad de voto y la protección de las minorías. Ello traería como consecuencia «el empezar a considerar territorialmente el impacto y consecuencias de los distintos proyectos legislativos producidos en el Congreso de los Diputados". Por otra parte, forzaria una mayor aproximación de los posicionamientos de los senadores a los intereses territoriales que representan, vinculando con mayor facilidad la opinión y criterios de los Gobiernos y Parlamentos de sus respectivas Comunidades Autónomas.

b) Utilización de lenguas propias de las Comunidades Autónomas, que asi las tengan reconocidas en sus Estatutos, en los trabajos parlamentarios.

c) Habilitación de oficinas de representación de los Gobiernos de las Autonomías; con ello "se trata únicamente de afirmar el carácter del Senado como casa común de todas las Comunidades Autónomas».

d) Posibilidad de debate ante el Pleno del Senado de proposiciones no de ley o mociones que sean presentadas por los Gobiernos o Parlamentarios Autonómicos, posibilitando para su defensa igual procedimiento que el previsto en el Congreso para tales iniciativas; a estas mociones o proposiciones se les dará carácter urgente o privilegiado.

e) El debate sobre el Estado de las Autonomías habrá de realizarse ante el Pleno del Senado, previa sesión informativa en Comisión, en la que podrán comparecer los representantes de las distintas Comunidades Autónomas, con el fin de «valorar la política autonómica del Gobierno y formular propuestas concretas de actuación». En esta sesión podrán estar presentes los presidentes de las Comunidades Autónomas o sus representantes.

f) Respecto a la designación para cubrir vocalías de organismos institucionales "la elección se hará de tal manera que los designados en cada renovación sean residentes de diferentes Comunidades Autónomas". 
g) Modificación de la Ley Orgánica del Tribunal Constitucional en lo que hace referencia a la forma de designación de sus magistrados y otros aspectos de su funcionamiento.

6. Documento elaborado por el Grupo Parlamentario de Senadores Nacionalistas Vascos en relación con la posible reforma del vigente Reglamento de la Cámara (26 de marzo de 1990)

En el preámbulo se pone de manifiesto la insuficiencia del carácter territorial de Senado, sustancialmente por la ruptura de la paridad entre Comunidades Autónomas, que deriva de su elección efectuada por provincias; se manifiesta, además, la subordinación del Senado al Congreso, incluso en materias autonómicas.

De lo dicho deriva la necesidad de una reforma orientada hacia las Comunidades Autónomas, así como una contribución al sistema autonómico, al mismo tiempo que es necesario desarrollar una función de integración. La reforma, que, en su caso, se acometa, nunca sería una panacea, sino que perseguiria el objetivo de una mayor funcionalidad de la Cámara. Existen dos vías para esta reforma tendente a convertir al Senado en Cámara de las Autonomías:

a) La reforma constitucional estableciendo una configuración global del Senado para la que solamente seria preciso el procedimiento previsto en el artículo 167 de la Constitución, que no exige disolución de las Cortes; para ello, sin embargo, sería "condición inexcusable contar con el soporte político necesario de la mayoría de las fuerzas políticas».

b) La segunda posibilidad se limita a la modificación del Reglamento del Senado, que «precisa también cierto grado de voluntad política en los partidos mayoritarios, para transformar la actual orientación».

Este grupo parlamentario entiende que según el artículo 69-1 de la Constitución que define al Senado como Cámara territorial y configurado ya el mapa autonómico, es preciso adaptar a estos principios todas las instituciones del Estado que lo precisen; «Las connotaciones autonómicas del Senado deben impulsarse para que la propia Constitución responda a las necesidades actuales".

Tras analizar las propuestas de otras fuerzas políticas, los senadores vascos deciden no presentar ninguna concreta, justificando esta postura al no entender este procedimiento el adecuado para lograr la potenciación del Senado como Cámara territorial, «a nuestro parecer la solución deseable consiste en la realización de un gran acuerdo político entre todos 
los partidos, ya que una tarea como ésta no puede ser obra de un solo partido o de unos pocos que formen mayoria». siguiente:

El contenido del acuerdo sugerido por el grupo parlamentario es el

- «No se rechaza la modificación del Reglamento del Senado para dotar a éste de un carácter territorial, aplicando las propuestas presentadas por algunos grupos parlamentarios, realmente innovadoras, mediante acuerdos parciales de detalle.

- Sin embargo, no parece suficiente puesto que se tiene el convencimiento de que para revitalizar con efectividad el Senado como Cámara territorial es necesario un consenso que sea asumido por todos los partidos políticos.

- Entendemos que este consenso nos va a permitir avanzar en la determinación de las competencias del Senado como Cámara de representación territorial al ir estudiando y profundizando todos los aspectos que integran el principio de competencia, intimamente conectado con el principio autonómico».

\section{E. Análisis global de las propuestas}

A la vista de las diferentes propuestas de los grupos parlamentarios del Senado, algo parece claro: la reforma de la Constitución o es obvia o, tácticamente, se pospone. En ambos casos se manifiesta la falta de voluntad política de afrontar una reforma, aunque sea parcial; ello por razones muy distintas pero, en este caso, convergentes en su no realización. En su momento ${ }^{64}$ pusimos de relieve una especie de respeto general hacia la consolidación del consenso que dio origen al sistema politico actual; sometido a reforma, serian muchas las necesidades técnicas y políticas de todo signo, incluso contradictorias, que se propondrían. Se puede constatar, a la vista de los documentos manejados, que en un tema tan puntual y concreto como es la reforma del Senado para convertirlo en auténtica Cámara territorial, se formulan dos posibilidades muy dispares y de dificil conjunción, v. gr., Convergència i Unió propone una segunda Cámara representante de los Gobiernos autonómicos, de composición proporcionada a su población, al modo del Bundesrat alemán; mientras que el partido Nacionalista Vasco, quizá en un afán excesivamente doctrinal, propone la

$64 \quad$ Vid. Epígrafe I. 
igualdad de las Comunidades Autónomas en su representación, al estilo de los Estados Unidos de América. No hace falta ser muy perspicaz para que; prescindiendo de prejuicios académicos, se observen problemáticas muy diversas ${ }^{65}$.

Existe, pues, una actitud unánime respecto a que la potenciación del Senado pase por su conversión en Cámara de representación territorial, quedando en lugar muy secundario su relevancia como Cámara de segunda lectura y, en este aspecto, las sugerencias de las fuerzas políticas se centran en los procedimientos de control del Gobierno, sobre todo por parte de los Grupos Parlamentarios Centro Democrático y Social y Popular.

Sólo es equiparable a esta necesidad de reforma del Reglamento de la Cámara, en función de la territorialidad del Senado, y no deja de ser consecuencia de ello, el que las propuestas se centren unánimemente en la participación de las Comunidades Autónomas en la vida parlamentaria, aunque con matices diferentes: bien la potenciación de los grupos territoriales (Partido Popular y Convergència i Unió), bien la creación o revitalización de Comisión o Comisiones territoriales (todos los Grupos, salvo Convergència i Unió y los Nacionalistas Vascos), bien participación activa de los órganos territoriales del Senado - los que se establezcan- en la legislación que tenga carácter territorial (con matices, Partido Socialista, Partido Popular, Centro Democrático y Social y Convergència i Unió) ${ }^{66}$.

Es preciso resaltar, asimismo, la necesidad de pacto político, que nadie rechaza, aunque es expresamente aprobado, como cuestión previa, por los Grupos Parlamentarios Socialista, Popular, Centro Democrático y Social y Nacionalistas Vascos; mención especial merece la sugerencia de este último Grupo que cifra toda la validez de la operación en que se logre ese consenso.

Los Grupos Parlamentarios Popular y Centro Democrático y Social manifiestan su preocupación por la carencia de cauce de participación de las Comunidades Autónomas en las decisiones de la Comunidad Europea que afecten a los intereses autonómicos, sugiriendo que sea el Senado el foro adecuado para lograr una información necesaria en relación con las cuestiones que tengan especial relevancia para los entes territoriales.

Cuestiones colaterales, pero no menos importantes, son las formuladas por el Centro Democrático y Social y Convergència i Unió en cuanto a la participación del Senado en la designación de miembros de los Órganos Constitucionales; en el caso de Convergència i Unió referido expresamente al Tribunal Constitucional. Por último son Izquierda Unida (Iniciativa per Catalunya) y Convergència i Unió quienes plantean como necesario

${ }_{65}$ Vid. Epígrafe 1.

66 En este punto el Grupo Parlamentario Nacionalista Vasco (PNV) no concreta debido al carácter genérico de su propuesta. 
el uso de las lenguas oficiales, aparte del castellano, en la vida parlamentaria del Senado.

\section{F. Acuerdo de la Ponencia}

Como ya se señaló, en Acuerdo adoptado por la Ponencia de la Comisión de Reglamento en su reunión de 25 de abril de 1990, se llegó a unos puntos mínimos de consenso en los que debería basarse la territorialización del Senado, siendo instrumento, a tal fin, la reforma de su Reglamento.

Según este Acuerdo, el objetivo prioritario de la reforma habrá de ser la promoción de la presencia en la Cámara Alta de las instituciones autonómicas, arbitrando los órganos necesarios para su cumplimiento. En cuanto a las funciones de estos órganos específicamente diseñados para la participación autonómica en el Senado, como no podia ser de otra forma si se mantiene el respeto a la Constitución, se reducen a cestudiar, tramitar, debatir, informar y dictaminar cuantos asuntos de interés autonómico hayan de conocer las Cortes Generales"; es decir, nunca deliberar, en el sentido de adoptar decisiones vinculantes. Asimismo, se señala que esta participación nunca podrá ser imperativa, sino basada en la colaboración; en consecuencia, se rechaza la posibilidad de que se susciten, desde éste o estos órganos, actos de control parlamentario, así como no otorga el uso de las prerrogativas parlamentarias a los participantes de las Comunidades Autónomas.

La generalidad del contenido de este Acuerdo, creo, permite un debate y una reforma del Reglamento del Senado que, desde un punto de vista más político que jurídico, incrementa en modo sustancial el papel a desempeñar en nuestro sistema. Es cierto que, a la vista de las propuestas formuladas, son muchas las disparidades existentes: se coincide en el fin, no así en cambio en los medios para llegar a él. Una lectura atenta del Acuerdo pone de relieve una cuestión de sumo interés; no son las Comunidades Autónomas, sino las instituciones autonómicas las que deben de estar en la base de la participación autonómica en el Senado. ¿Qué instituciones? ¿Los Gobiernos producto de una mayoría a intra? o ¿las Asambleas legislativas en su pluralidad política?, ¿los Gobiernos con mayoría absoluta o los productos de una coalición?, ¿las Asambleas en su mosaico ideológico o sus órganos representativos ostentadores de las mayorías ad hoc? Ejemplos de todo existen en nuestras diecisiete Comunidades Autónomas. Si a esto añadimos partidos políticos de implantación nacional, partidos nacionalista más partidos regionalistas de muy diverso tipo, implica no pocos problemas.

Del texto del Acuerdo se deduce, y no podía ser de otra manera, que no es la Comunidad Autónoma como tal, ni su población, quienes van a 
asumir esas funciones. Puede parecer una cuestión baladi, sin embargo tiene gran importancia no por lo que pueda significar en este pequeño pero significativo paso en el desarrollo de nuestro Estado, sino porque estas ideas apuntan en una determinada dirección: En el fondo se está prejuzgando la naturaleza de la participación de las Comunidades Autónomas en la formación de la voluntad del Estado ${ }^{67}$ en un futuro más o menos próximo, si la tendencia fuese la federalización en sentido clásico. En la misma línea, no sólo ope constitutionis sino también ope politicae, se encuentra la negativa a proporcionar a los representantes de las Autonomias los privilegios y la calidad de senadores.

El documento citado aporta un valor de primera magnitud, que es el Acuerdo, pero no desentraña el mecanismo necesario para llevarlo a buen fin, aunque apunta los mínimos básicos; en el cuadro adjuntado se hace un resumen de las propuestas concretas que están en la base del Acuerdo examinado; de una manera gráfica se expresa claramente el consensodisenso respecto a cuáles han de ser las fórmulas.

\section{CUADRO SOBRE LAS PROPUESTAS DE LOS GRUPOS PARLAMENTARIOS DEL SENADO RESPECTO A LA REFORMA DE LA CÁMARA}

\begin{tabular}{lcccccc}
\hline & PSOE & PP & CDS & IU & CiU & PNV \\
\hline $\begin{array}{l}\text { Reforma de la } \\
\text { Constitución .......... }\end{array}$ & - & - & - & sí & sí & sí \\
\hline $\begin{array}{l}\text { Reforma del } \\
\text { Reglamento } \\
\text { del Senado ............. }\end{array}$ & si & si & sí & sí & sí & sí \\
\hline
\end{tabular}

${ }_{67}$ De acuerdo con el esquema propuesto para interpretar la naturaleza compuesta del Senado, es de fácil deducción que la reforma de este órgano va dirigida a convertirlo de facto en una Cámara «suprema" en la coordinación entre el Estado y las Comunidades Autónomas; en cambio, la otra faceta que posee una Cámara territorial en un Estado compuesto, va más allá, al menos desde un punto de vista técnico: posibilita la participación, no de facto sino de iure, de los entes territoriales en la formación de la voluntad estatal, en aquellas materias que les afecten. 
(continuación)

PSOE PP CDS IU CiU PNV

Grupos territo-

riales

- S S

sí

$-\quad-$

sí

-

Comisiones

territoriales

si sí

Si

sí

Participación de

las Comunidades

Autónomas

Sí Sí

sí

Sí

sí

sí

\section{Participación \\ en legislación \\ territorial}

sí

sí

sí

sí

sí

-

\section{Debate Auto-}

\begin{tabular}{|c|c|c|c|c|c|c|}
\hline nomías .......................... & - & 一 & sl & si & sil & - \\
\hline Uso lenguas ............. & 一 & 一 & - & si & sí & 一 \\
\hline $\begin{array}{l}\text { Designación } \\
\text { vocales de } \\
\text { órganos consti- } \\
\text { tucionales ............... }\end{array}$ & - & 一 & sí & - & sí & - \\
\hline Pacto político ........... & sí & sí & si & 一 & - & sí \\
\hline 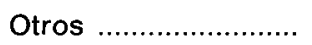 & - & si & si & - & sí & - \\
\hline
\end{tabular}

\section{CONSIDERACIONES FINALES}

A. Pudiera parecer ocioso, a la vista de lo anterior, un análisis tan pormenorizado, debido a la humildad del ámbito de operaciones de la re- 
forma propuesta a causa de las limitaciones constitucionales; es decir, el esfuerzo que suponga la reforma del Senado, al menos desde un punto de vista técnico-juridico, no va a resolver el problema de la territorialización de la Cámara; pero si nos detenemos a pensar en su significado creo que debe ser otro el criterio, y ello por las siguientes razones:

1. Supone la vuelta, al menos en intención, a la vía consensuada entre los distintos partidos políticos de ámbito nacional y autonómico.

2. Las propuestas que se han efectuado, pese a los distintos enfoques, pueden constituir la base que permita disminuir diferencias, en ocasiones más teóricas que reales, respecto al definitivo cierre del proceso autonómico diseñado en la Constitución.

3. A pesar del mínimo valor que implica la reforma propuesta a la hora de tomar auténticas decisiones, el Senado puede ser la institución que acoja el embrión de todas aquellas iniciativas que propugnen la, en su caso, solución definitiva a las carencias técnicas que posee nuestro texto constitucional, en cuanto a las relaciones de coordinación e inordinación, según el esquema propuesto; es decir, a la ausencia de participación de los entes territoriales en la formación de la voluntad estatal. Nada mejor que esas deficiencias se traten en sede parlamentaria, sin despreciar, por descontado, las que se lleven a cabo en otros ámbitos.

B. EI profesor ARAGÓN REYES ${ }^{68}$, recientemente, ha hecho la propuesta de una tercera vía para proceder a la reforma del Senado a través de la ley orgánica que prevé el artículo 69,2 de la Constitución, que, en mi opinión, plantea más problemas de los que resuelve, desde un punto de vista político, y responde a la concepción fijada en el texto constitucional de representación ideológica, subordinación del Senado, etc. Es decir, la idea se apoya en los siguientes criterios:

1. La consideración de la inoportunidad política de una reforma constitucional.

2. Los escasos medios de que se dispone, desde el punto de vista técnico, para convertir al Senado en Cámara territorial.

68 En «El Pacto Autonómico», El Sol, dias 29 y 30 de julio de 1991. 
3. La duda, más que profunda, sobre la valiosidad de la reforma del Reglamento, que nos dejaría, desde el punto de vista técnico-juridico, en el mismo lugar en que nos encontramos.

Pese a la originalidad de la propuesta -auténtica ingeniería juridica- le veo defectos de fondo muy profundos. La naturaleza de las leyes orgánicas en nuestro sistema constitucional implica la participación subordinada del Senado en su elaboración. Ante esto, ¿dónde queda el principio de autonomía de la Cámara?, ¿hasta qué punto puede alcanzar esa ley orgánica?, técnicamente no podrá ir más allá de lo que pueda hacerse por via reglamentaria. La regulación por ley orgánica puede, efectivamente, solucionar cuestiones como las planteadas por el $\mathrm{CDS}^{69}$ en relación con la simultaneidad de elecciones senatoriales y autonómicas, incluso modificaciones del sistema electoral; nunca podrá afectar al status competencial del Senado establecido constitucionalmente.

La valiosidad de la propuesta radica en el intento de ir más allá de lo que puede suponer la reforma del Reglamento, desde el punto de vista técnico-jurídico, y evitar la reforma constitucional. Sin embargo, rechazada políticamente y de momento la reforma de la Constitución, la vía de regulación del Senado a través de ley orgánica, tiene un problema de difícil superación: more politicae, el subrayado de la preeminencia del Congreso —léase representación ideológica — frente a la representación territorial.

Atados a un deseo generalizado de obviar la reforma constitucional, la fórmula del profesor Aragón puede ser válida en lo que afecta a la legislación electoral y a los problemas derivados de ella respecto al Senado, pero no directamente respecto a esta Cámara: puede incidir en ésta pero poco más añade.

C. Creo que es de singular importancia el valorar las propuestas de reforma del Reglamento del Senado hechas por los grupos parlamentarios y la consolidación de usos y prácticas en la Cámara - muy débiles e incipientes pero que tenderán, como siempre sucede, a institucionalizarse- que generen un ámbito de debate -desde el punto de vista que se desee- entre el Estado y las Comunidades Autónomas; ámbito sólo existente hoy en lo que podriamos denominar terreno administrativo. Las relaciones de coordinación - ya que no se admite en las de inordinaciónprecisan un foro estatal parlamentario; la estructura de un Estado compuesto - dígalo o no la Constitución, y lo dice- precisa ese foro de encuentro al más alto nivel. 
D. La problemática ad extra de la integración europea, en la que son los Ejecutivos quienes deciden, con nula participación, en la práctica, de los otros poderes del Estado, requiere un lugar en el que el Estado y las Comunidades Autónomas se informen reciprocamente; en el que se provea a éstas de los datos necesarios para conocer las repercusiones que territorialmente conllevan las decisiones del Gobierno y pueda participarse en las políticas legislativas y de control al respecto.

E. Por todo lo dicho, creo que el intento de reforma del Reglamento del Senado, en un cabal entendimiento de lo que significa desde el punto de vista técnico-constitucional, va más allá, si se administra políticamente de modo adecuado; es decir, puede suplir, por la vía de reglamentación de prácticas y usos - hasta hoy muy humildes e insignificantes si se les valora desde la dogmática - el ámbito de debate, discusión y propuesta de las decisiones a adoptar en otras esferas ${ }^{70}$.

F. No se trata de propugnar una vía espúrea, que conduzca a la desconstitucionalización efectiva - vía mutación constitucional- del Senado; se trata de dar solución, en una institución prevista en el Estado global, a la necesidad de una Cámara realmente ejerciente de las funciones que le corresponden en un Estado compuesto: coordinación e inordinación.

G. He intentado poner de relieve el poco interés que suscita la palabra federal en la actualidad, con independencia de lo que se sienta o se crea que significa. De facto nos hallamos, y asi ha sido reconocido por la doctrina, en una situación cuasi federal ${ }^{71}$, de federalismo de ejecución ${ }^{72}$, de federalismo de cooperación ${ }^{73}$, de unitarismo federalizante ${ }^{74}$, etc. En consecuencia hay que olvidarse de la palabra y de sus connotaciones históricas disgregadoras, $y$, ateniéndose a la realidad, completar lo que exige -en mi opinión - un Estado compuesto. Si técnicamente exige una reforma

70 La naturaleza de las cosas impone su realidad; la creación legal de foros de participación a nivel administrativo (LOFCA, Consejo de Universidades, Conferencias de distinto tipo, etc.) no resuelven el problema.

${ }^{71}$ Vid. E. GARCIA DE ENTERRIA: «El futuro de las autonomias territoriales», en España: un presente para el futuro, IEE, Madrid 1984.

72 Vid. A. JIMENEZ BLANCO: «Las relaciones de funcionamiento entre el Poder Central y los entes territoriales", IEAL, Madrid 1985. Madrid 1984.

${ }^{73}$ Vid. P. SantaOlaya Machetti: eDescentralización y cooperación», IEAL,

74 Vid. J. J. Gonzalez Encinar: El Estado unitario-federal, Tecnos, Madrid 1985. 
constitucional, hágase; si el coste, según las fuerzas políticas parlamentarias, es muy elevado, rechácese, pero deben facilitarse todos los medios politicos y jurídicos que conduzcan a una complementación de las carencias que, desde el esquema de un Estado compuesto, se han puesto de relieve en este estudio.

Pese a todo, es preciso ser consciente de que no existe una voluntad política clara de que las Comunidades Autónomas participen, como tales, en la formación de la voluntad del Estado. 